\title{
Marriage Premium and Class *
}

\author{
Roberto Bonilla \\ Newcastle University, UK Newcastle University, UK \\ John Wildman \\ Newcastle University, UK
}

11 June 2017

\begin{abstract}
We present an equilibrium model with inter-linked labour and marriage markets and argue that search frictions play an important role in explaining the male marriage wage premium. If within households men are viewed as breadwinners, this expectation affects their job search behaviour and it can lead to (rankable) marital earnings gaps. Male productivity heterogeneity is neither necessary nor sufficient for such marriage premium. However, with additional female heterogeneity in the marriage market, the reservation wages chosen by men who differ in productivity also determine equilibrium marriage classes which in turn have their own patterns of marital wage differentials. Using UK data on wages, male and female heterogeneity as well as marriage classes, we carry out the first empirical test of the role of search frictions in generating male marriage wage premium.

Keywords: frictional labour markets, frictional marriage markets, marriage premium, classes.

JEL classification: D83, J12, J64

*We are grateful for comments received from Jim Albrecht, Carlos Carillo-Tudela, Melvyn Coles, Marco Francesconi, Adrian Masters, Guido Menzio, Fabien Postel-Vinay, Alberto Trejos, Ludo Visschers and Susan Vroman, as well as participants at the Search and Matching Annual Meeting (Aix-en-Provence, 2015), Search and Matching Workshop (Essex, 2015) and seminar participants at SUNY Albany, Fribourg, Geneva, Munich and Neuchatel. Bonilla would also like to thank SUNY Albany and University of Oviedo for their hospitality while working on this project.
\end{abstract}




\section{Introduction}

Why do married men generally earn more than unmarried men? The question has intrigued the economics profession for a long time, as the so-called male marriage premium has consistently been found to be anywhere between $10 \%$ and $40 \%$ or even as high as $50 \%$. In sharp contrast, the female marital earnings gap is negative and much smaller in magnitude.

The current literature offers two broad explanations which differ in terms of the direction of causality they favour. According to the specialisation theory developed by Becker $(1973,1974,1985,1991)$ and Mincer and Polachek (1974), marriage allows for economies of scale and intra-household specialisation of labour, with men being able to focus on formal employment, which in turn tends to enhance productivity and earnings. In a similar vein, Grossbard-Shechtman and Neuman (2003) note that the spouse also increases a married man's productivity directly by enhancing his human capital and general well-being.

In turn, proponents of the selection hypothesis such as Nakosteen and Zimmer (1987), Davies and Peronaci (1997) and Gray (1997) argue that men who are more productive at work and /or earn high wages are more likely to get married. This may be the case if some traits that make men more productive in the labour market (such as loyalty, honesty and dependability) are also valued in the marriage market. Interestingly, this selection effect could also work indirectly through labour market gender discrimination, with employers favouring married men because they too associate marriage with productivity-enhancing traits.

Two important questions arise. First, why is there no female marriage premium? After all, there is no obvious reason why the above logic should not hold symmetrically for both sexes. Needless to say, women are just as likely to have unobservable characteristics that are valued both in employment and marriage, so why is the selection argument presumed one-sided? In turn, unless there are explicit gender differences which stem from comparative advantages in human capital accumulation, labour market discrimination or intra-household bargaining positions, the specialisation argument is also biased.

Of course, with the marked qualitative difference between observed male and female marriage premia, this unequal treatment is a reasonable ad hoc as- 
sumption. In our opinion, however, it obscures the key fact that whatever the source of such asymmetry, it all boils down to men apparently being regarded as providers in a household. Whether this is the case simply because of attitudes towards marriage or it derives from family members' differing options in the labour market, it is this (possibly self-fulfilling) belief that ultimately underpins the behaviour of marriage partners under both approaches. We argue that such expectations within a household should be made explicit, as they affect the entire job finding process and hence the wages earned by men.

Second, it is apparent that existing explanations of male marriage wage differentials follow the standard neoclassical approach which tends to equate human capital with earnings. But if one takes the job finding process seriously and considers search behaviour in frictional labour markets, productivity and wages can no longer be assumed inter-changeable. In turn, this means that the link between male productivity and marriage as assumed by the specialisation and selectivity theories may not be quite so straightforward either.

What is needed therefore is an equilibrium analysis, with male wage differentials as possible outcomes in a framework where labour market decisions are influenced by expectations and behaviour in the marriage market, and vice-versa. Naturally, this framework should also include search frictions, as it takes time, effort and luck to find a job and a suitable marital partner.

To achive this, we construct a model where the two frictional markets are inter-linked. In the marriage market, men and women engage in two-sided sequential search for partners. Women prefer high earners (breadwinners) and this is common knowledge. In our setup, these marriage market expectations are neatly captured by women's reservation match value.

In turn, unemployed men engage in job search, knowing that their earnings determine whether or not they can get married. Formalising this sequential decision problem is, however, far from trivial, as one needs to capture the possibility of a man encountering wages that make him marriageable or not. To that end, we introduce and analyse the so-called constrained search problem facing an unemployed male. This variant of the standard sequential job search constitutes the bridge between the two markets in the sense that the optimal strategy (reservation wage) is now a function of marriage market expectations. 
In a preliminary study, Bonilla and Kiraly (2013) show that a male marriage premium can indeed be an equilibrium outcome in a setup where men are homogeneous in terms of productivity. Here, we expand that simple model in two important ways. In order to gain a better understanding of the role of search frictions and productivity differences in generating patterns of marital wage premia, we first allow for male heterogeneity in the labour market. Following that, we augment the model by also including female heterogeneity, with women having different levels of attractiveness in the marriage market. The setup with two-sided heterogeneity provides a natural framework to examine the question of who marries whom.

We make several contributions in this paper. First, with one-sided heterogeneity, we confirm that a positive male marriage premium can obtain in equilibrium. The key insight is that with job search, the optimal stopping strategy determines both the probability of getting married and the average wages earned by various groups of men.

We show that with random sequential constrained job search, the optimal reservation wage may in fact be set so low that it precludes marriage. The logic is quite intuitive: although marriage leads to an increase in utility for a man, the opportunity cost of holding out for a wage acceptable to women may outweigh this utility gain if the required well-paid jobs are relatively difficult to encounter. As a result, there will be single men on relatively low wages and men who can marry because they have good jobs.

Second, we establish that ex-ante productivity heterogeneity is neither a necessary nor a sufficient condition for the existence of male marriage premium. That is, such wage differentials can exist within each male productivity group, while the pattern of rankable marriage premia across productivity types does not exclude the possibility of same (zero) marital earnings gaps for different types of men.

Third, we examine the endogenous formation of marital classes where the sorting occurs along male wages and female levels of attractiveness. Crucially however, the distribution of wages earned by males is now itself determined endogenously, through the optimal reservation wage strategies of different men. This is in contrast with the setup used in the seminal Burdett and Coles (1997) paper and virtually all subsequent work on assortative matching in the presence of search frictions, which assume an exogenous distribution of 
wages. ${ }^{1}$ To that end, we construct an equilibrium with two classes, establish the existence of a bottom class and characterise marital partnerships in terms of male marriage premia.

Fourth, we carry out the first empirical investigation of the role of search frictions in explaining the male marital earnings gap. ${ }^{2}$ Our findings strongly indicate that marriage premia follow indeed the patterns across male productivity types suggested by our model. Furthermore, in our sample we find evidence of assortative matching and a bottom marital class, where men with very low socio-economic characteristics exhibit a zero marriage premium and are in partnerships with similarly "below average" women.

The existing literature on male marriage premium, excellently surveyed by Grossbard-Shechtman and Neuman (2003), Daniel (1995) and Hersch (2003), is almost exclusively empirical in nature. In the main, the studies use either cross sectional data or models with panel data, as well as some econometric models based on marriage market analysis. The standard methodology is to allow for individual-specific fixed effects in order to eliminate unobserved heterogeneity. Korenman and Neumark (1991), Cornwell and Rupert (1995) and Schoeni (1995) are good examples of this approach.

Although much of the empirical work appears to confirm the existence of a link between productivity differences and male marriage wage premium, the evidence in support of either the selection or specialisation explanations is exasperatingly mixed.

The results of Chun and Lee (2001) suggest that the selection effect is minimal, while Ginther and Zavodny (2001) find that only up to $10 \%$ of wage premium is the result of selection. In contrast, Loh (1996) and Hersch and Stratton (2000) argue that the effect of a potential productivity increase after marriage is also quite weak. Blackburn and Korenman (1994) consider evidence for both theories but conclude that neither seem to be sufficient explanations for the existence of marriage premium. More recently, Antonovics

\footnotetext{
${ }^{1}$ The only other paper we are aware of that looks at endogenous marriage partner traits is Chiappori et al. (2009), which includes an ex-ante choice of investment in education.

${ }^{2}$ The need for such an empirical appraisal of the role of frictions in explaining male marriage premium is stressed in Ponthieux and Meurs (2014). Incidentally, Bonilla et al.(2015) also provide evidence of the link between market frictions and marriage premium, but their focus is on testing the search theoretical approach to beauty premium.
} 
and Town (2004) use an US sample that includes twins, and reach the conclusion that the observed male marital premium cannot be explained by the selection hypothesis. In contrast, Bardasi and Taylor (2008) use UK panel data and remark that although household specialisation is a relevant contributing factor, the earnings gap is more likely to be the result of a selection effect.

It is apparent therefore that the evidence gathered so far is not in a position to settle the question, and the controversy goes on. Perhaps a new approach is needed. In an illuminating paragraph which we quote in full, Grossbard-Shechtman and Neuman (2003) highlight the problems facing empirical research on marriage premium and stress the need for a fresh angle: "What such fixed-effects models tell us is what part of the marital differentials are due to selectivity into marriage and what part are productivity-enhancing effects of marriage. However, the selectivity effect could be a breadwinner effect: It could be that an unmeasured motivation to marry had led men to enhance their labor market productivity and earnings, knowing that this would increase their chances of getting married. So identifying a sequence running from productivity to marriage does not prove that it is not marriage that makes men more productive. If selectivity effects are breadwinner effects, it is the prospect of marriage that makes men more productive."

In this context, we hope that the market equilibrium approach we propose, which incorporates search frictions as well as the breadwinner hypothesis will prove to be a fruitful contribution to the debate about the sources of male marriage premium.

The rest of the paper is structured as follows. First, we describe the model with male heterogeneity. Section 3 establishes the existence of a search equilibrium with marriage premium and examines the effect of male productivity differences. Section 4 considers the augmented framework with two-sided heterogeneity. There, we construct a search equilibrium with two marital classes characterised by specific marriage premium patterns. Next, an empirical section provides evidence in support of our theory. Concluding remarks appear in Section 6. 


\section{The model}

The economy consists of a continuum of women and men, all risk neutral. Time is continuous and all agents discount the future at rate $r$. Only steady state equilibria are considered.

Men enter the economy unemployed and single. We first consider the scenario with two types of men who differ in terms of productivity. The subscript $i$ (where $i=L, H$ ) denotes low- and high productivity type, respectively. Let $u_{i}$ denote the steady state measure of single unemployed men of type $i$.

In the labour market, unemployed men use costless random sequential job search, and contact with a firm occurs at rate $\lambda_{0}$, identical for the two types. A type $i$ unemployed draws an offer from the exogenous wage distribution $F_{i}(w)$ with support $\left[\underline{w}_{i}, \bar{w}_{i}\right]$, and we assume that $\underline{w}_{L}<\underline{w}_{H}, \bar{w}_{L}<\bar{w}_{H}$ and $F_{L}(w)>F_{H}(w)$. A single man who is employed at wage $w$ has flow payoff $w$. There is no on-the-job search and no job destruction, so a man's wage remains constant throughout his working life.

All single men look for potential female marital partners. Women can observe a man's employment status, his productivity and earned wage. In the marriage market, meetings occur according to a quadratic matching function, where the number of meetings is proportional to the product of the measure of searchers on each side of the market. This (see Mortensen, 1982) gives rise to a Poisson meeting technology with an arrival rate that is a linear function of the relevant measure of participants on the opposite side of the market. For men of type $i$, we denote this arrival rate by $\lambda_{m}^{i}$. A married man earning wage $w$ enjoys flow payoff $w+y$, where $y>0$ captures the utility of marriage. Assume that $y$ is the same for both types of men, and there is no possibility of divorce.

Let $n$ denote the measure of single women, and let $x$ denote the exogenous flow payoff of a single woman. Women do not look for jobs ${ }^{3}$, but use costless random sequential search to locate single males. Let $\lambda_{w}^{i}$ and $\lambda_{w}^{u}$ be the parameters of the Poisson process and hence the rate at which a woman meets a type $i$ employed man or an unemployed, respectively. Upon contact, a woman decides whether to accept or reject a marriage proposal. Let $N_{i}$

\footnotetext{
${ }^{3}$ If they did, $x$ could of course be endogenous, just as it would under any other scenario where women are active in the labour market.
} 
denote the measure of employed single men of type $i$ who are acceptable to women. A married woman's flow payoff is equal to her partner's wage earnings. Upon marriage a woman gives up $x$, so we assume that $x<\bar{w}_{L}$ in order to ensure that a marital partnership with either type of man does indeed have a positive potential surplus. ${ }^{4}$

Marriages are for life, but couples and singles alike leave the economy at an exogenous rate $\delta$. Every time an unemployed single man of type $i$ accepts a job, gets married or leaves the economy, he is replaced by another type $i$ unemployed single man. Hence, $u_{i}$ can be treated as exogenous. Similarly, we assume that a new single woman enters the economy every time a single woman gets married or exits, so $n$ can also be regarded as exogenous.

Denote by $\lambda$ the parameter which measures the efficiency of the meeting process. Let $N_{i}$ denote the measure of employed marriageable single men of type $i$. Then, from a single man's point of view, the average instantaneous rate at which meetings occur is $\lambda_{m}^{i}=\frac{\lambda\left(N_{H}+N_{L}\right) n}{\left(N_{H}+N_{L}\right)}=\lambda n$. Similarly, from the point of view of single women, the rate at which meetings with unemployed men occur is $\lambda_{w}^{u}=\frac{\lambda\left(u_{H}+u_{L}\right) n}{n}$, while the corresponding rate of meeting employed men of type $i$ is $\lambda_{w}^{i}=\frac{\lambda\left(N_{H}+N_{L}\right) n}{n} \frac{N_{i}}{\left(N_{H}+N_{L}\right)}=\lambda N_{i}$. The steady state measure $N_{i}$ is of course endogenous, and consequently so is $\lambda_{w}^{i}$, together with the steady state measures of unmarriageable men of type $i$ (bachelors, denoted by $B_{i}$ ) and of married men of type $i$ (denoted by $M_{i}$ ).

Before we proceed with the analysis, we define the marriage premium among type $i$ men $\left(M P_{i}\right)$ as the difference between the average wage of type $i$ married men $\left(\widetilde{w}_{i}^{M}\right)$ and the average wage of type $i$ single men $\left(\widetilde{w}_{i}^{S}\right)$. Throughout, superscripts $S$ and $M$ stand for "single" and "married", respectively. Finally, in the context of the paper, "marriageable" and "eligible" are used interchangeably.

\footnotetext{
${ }^{4}$ Blundell et al. (2015) show that female attachment to the labour market weakens considerably after marriage. This has an immediate impact on their earnings (due to nonparticipation), but also a lasting impact in the form lower future wages and part time work even after reattachment to the labour market. In turn, Gould and Passerman (2013), Openheimer (1988), Oppenheimer and Lew (1995), Loughran (2002) and Loughran and Zissimopoulos (2009) provide evidence that women build this into their expectations and behaviour in the marriage market.
} 


\section{Marriage Premium}

Given sequential search and the fact that utilities are increasing in wages, we show that women and men alike use optimal strategies characterised by the reservation property. However, crucially, men's best response is in fact a reservation wage function $R_{i}\left(T_{i}\right)$, where $T_{i}$ is the reservation match of women.

\subsection{Women}

In this section, we first establish that women refuse to marry unemployed men of type $i$ if the reservation match of females is high enough. To see that, consider a married and employed man of type $i$. Without the possibility of either on-the-job search or divorce, and conditional on survival, standard considerations give the discounted expected lifetime utility:

$$
V_{i}^{M}(w)=\frac{w+y}{r+\delta}
$$

Although the above utility is clearly independent of productivity type, in the interest of clarity we will continue to use these subscripts when referring to this employment value.

Now consider a married but unemployed man of type $i$. If such a man receives a wage offer $w$ and behaves optimally in each period, the relevant Bellman equation is:

$$
v_{i}^{M}(w)=\max \left\{V_{i}^{M}(w), J_{i}^{M}\right\}
$$

In the above, $J_{i}^{M}$ denotes a jobless married man's value from continued job search, and it is given by:

$$
J_{i}^{M}=\frac{1}{r+\delta+\lambda_{0}}\left[y+\lambda_{0} \int_{\underline{w}_{i}}^{\bar{w}_{i}} v_{i}^{M}(w) d F_{i}(w)\right] .
$$

Above, the right-hand side captures the expected discounted return. Recall that $y$ is the instantaneous utility from a marital partnership, while the second term in the brackets describes the expected utility of any change in the value of this man's state, computed as the probability he receives a job offer $\left(\lambda_{0}\right)$ times the expected continuation value associated with the wage offer $w$, given that the offer can of course be rejected. 
Note that $J_{i}^{M}$ is independent of any current wage offer. In turn, $V_{i}^{M}(w)$ is continuous and increasing in the accepted offer $w$, so the optimal strategy has the reservation property. Denote the relevant reservation wage by $R_{i}^{M}$, and manipulate the above equation to obtain the familiar version:

$$
(r+\delta) J_{i}^{M}=y+\lambda_{0} \int_{R_{i}^{M}}^{\bar{w}_{i}}\left[V_{i}^{M}-J_{i}^{M}\right] d F_{i}(w) .
$$

Given the above, the married man's reservation wage $R_{i}^{M}$ solves the standard equation:

$$
J_{i}^{M}=V_{i}^{M}\left(R_{i}^{M}\right)=\frac{R_{i}^{M}+y}{r+\delta},
$$

and we get:

$$
R_{i}^{M}=\frac{\lambda_{0}}{r+\delta} \int_{R_{i}^{M}}^{\bar{w}_{i}}\left[w-R_{i}^{M}\right] d F_{i}(w) .
$$

Further integration by parts leads to:

$$
R_{i}^{M}=\frac{\lambda_{0}}{r+\delta} \int_{R_{i}^{M}}^{\bar{w}_{i}}\left[1-F_{i}(w)\right] d w \equiv \underline{R}_{i}
$$

Importantly, $\underline{R}_{H}>\underline{R}_{L}$, because the two types of men face different prospects in the labour market.

Furthermore, $\underline{R}_{i}$ is also the reservation wage of type $i$ unemployed men in a standard sequential job search problem where there is no link with the marriage market. As we will show later, $\underline{R}_{i}$ is in fact the lowest reservation wage for each type.

In principle, women could of course marry unemployed men too. Let us therefore examine the situation of a woman who is married to a jobless type $i$ man. Introducing the subscript $U_{i}$ to denote marriage to such an unemployed, her value function $W_{U_{i}}^{M}$ is given by:

$$
(r+\delta) W_{U_{i}}^{M}=\lambda_{0} \int_{\underline{R}_{i}}^{\bar{w}_{i}}\left[W_{i}^{M}(w)-W_{U_{i}}^{M}\right] d F_{i}(w),
$$

where $W_{i}^{M}(w)=\frac{w}{r+\delta}$ is the discounted lifetime utility of being married to a type $i$ employed man who earns wage $w$. The interpretation is straightforward: the flow value of being married to a type $i$ unemployed man is 
essentially the potential benefit from any increase in her utility if the man finds and takes up a job offer $w$.

For $T_{i}$ to be a female reservation match, it needs to satisfy $W_{U_{i}}^{M}=\frac{T_{i}}{r+\delta}$. Making use of $W_{i}^{M}(w)$ above leads to:

$$
(r+\delta) W_{U_{i}}^{M}=\frac{\lambda_{0}}{r+\delta} \int_{\underline{R}_{i}}^{\bar{w}_{i}}\left[w-T_{i}\right] d F_{i}(w) .
$$

Since the right-hand side is equal to $\underline{R}_{i}$ for $T_{i}=\underline{R}_{i}$, we have:

$$
(r+\delta) W_{U_{i}}^{M}=T_{i}=\underline{R}_{i}
$$

On the other hand, for $\underline{R}_{i}<T_{i}$ we instead have:

$$
(r+\delta) W_{U_{i}}^{M}>\underline{R}_{i}
$$

Therefore, women reject marriage to a type $i$ unemployed man if $T_{i}>\underline{R}_{i}$ For the rest of Section 3, we work under the assumption that this is indeed the case. ${ }^{5}$

Next, we derive the women's reservation match (wage) $T_{i}$.

First, note that when a woman turns down an employed man, she returns to the same pool of potential partners. From her point of view, the expected value of continued search is therefore independent of the wage she rejected, and reflects the mix of high- and low productivity men.

Second, as there is no job destruction and a married woman's instant utility is not affected directly by her partner's productivity, the lifetime utility of accepting a man with a wage $w$ is simply the discounted value of that wage: $\frac{w}{r+\delta}$, which is clearly continuous and increasing in $w$.

Overall, this means that with sequential search, the optimal stopping strategy has the familiar reservation property: a woman will accept a type $i$ man as long as his wage is at least as high as $T_{i}$.

From the point of view of a single woman, the key considerations are: the number of single marriageable employed men of each type $\left(N_{i}\right)$, and

\footnotetext{
${ }^{5}$ By doing so, we eliminate the uninteresting (for the purpose of this section) equilibrium where the marriage market does not affect job search. However, we do allow for this in Section 4.
} 
the wages earned by these eligible single men, captured by the distribution function $G_{i}($.$) . Therefore, in order to compute a single woman's utility, it is$ helpful to determine $\left(N_{i}\right)$ and $G_{i}($.$) first.$

Eligible men of type $i$ get married at rate $\lambda n$ and die at rate $\delta$, while unemployed men of type $i$ find marriageable wages at rate $\lambda_{0}\left[1-F_{i}\left(T_{i}\right)\right]$. Therefore, the steady-state equation for $N_{i}$ is:

$$
N_{i}(\lambda n+\delta)=u_{i} \lambda_{0}\left[1-F_{i}\left(T_{i}\right)\right],
$$

which gives

$$
N_{i}=\frac{u_{i} \lambda_{0}\left[1-F_{i}\left(T_{i}\right)\right]}{\lambda n+\delta}
$$

In turn, $G_{i}($.$) is obtained from N_{i}$ above, together with the inflow-outflow equation:

$$
u_{i} \lambda_{0}\left[F_{i}(w)-F_{i}\left(T_{i}\right)\right]=(\delta+\lambda n) N_{i} G_{i}(w)
$$

From here, we get:

$$
G_{i}(w)=\frac{F_{i}(w)-F_{i}\left(T_{i}\right)}{1-F_{i}\left(T_{i}\right)} .
$$

Before we turn to the female reservation match, let us complete the picture by finding the steady state measures of bachelors $\left(B_{i}\right)$ and married men $\left(M_{i}\right)$, together with their respective wage distributions. Bachelors are men who have accepted jobs that make them un-marriageable, so their inflowoutflow equation is:

$$
u_{i} \lambda_{0}\left[F\left(T_{i}\right)-F\left(R_{i}\right)\right]=\delta B_{i}
$$

Let $E_{i}(w)$ denote the distribution of wages amongst these men. We have:

$$
u_{i} \lambda_{0}\left[F(w)-F\left(R_{i}\right)\right]=\delta B_{i} E_{i}(w),
$$

and therefore:

$$
E_{i}(w)=\frac{F(w)-F\left(R_{i}\right)}{F\left(T_{i}\right)-F\left(R_{i}\right)} .
$$

In turn, the steady state condition for the measure of married men is simply:

$$
\lambda n N_{i}=\delta M_{i}
$$


Finally, as the rate at which marriageable men get married and the rate at which married men exit the economy are both independent of their wages, the distribution of wages earned by type $i$ married men is also $G_{i}(w)$.

We now turn to the reservation match set by women. Recall that the rate at which a woman meets an eligible single employed man of type $i$ is $\lambda_{i}^{w}=\lambda N_{i}$. Denote the expected value of being single for a woman by $W^{S}(w)$. Then, provided $T_{i}>\underline{R}_{i}$ for both male types, we have:

$$
\begin{aligned}
(r+\delta) W^{S}(w)= & x+\lambda N_{H} \int_{T_{H}}^{\bar{w}_{H}}\left[\frac{w}{r+\delta}-W^{S}\right] d G_{H}(w)+ \\
& +\lambda N_{L} \int_{T_{L}}^{\bar{w}_{L}}\left[\frac{w}{r+\delta}-W^{S}\right] d G_{L}(w) .
\end{aligned}
$$

Making use of (2) and (3), one obtains the alternative expression:

$$
\begin{aligned}
(r+\delta) W^{S}(w)= & x+\frac{\lambda u_{H} \lambda_{0}}{\lambda n+\delta} \int_{T_{H}}^{\bar{w}_{H}}\left[\frac{w}{r+\delta}-W^{S}\right] d F_{H}(w)+ \\
& +\frac{\lambda u_{L} \lambda_{0}}{\lambda n+\delta} \int_{T_{L}}^{\bar{w}_{L}}\left[\frac{w}{r+\delta}-W^{S}\right] d F_{L}(w)
\end{aligned}
$$

The left-hand side is the flow value for a single woman. On the right-hand side, we have the instantaneous utility $x$ plus the expected increase in utility that results from any change in the value of her state, which is computed as the probability she meets an eligibe type $i$ employed man times the expected increase in value. Since $W^{S}(w)=T_{i} /(r+\delta)$, we have $T_{H}=T_{L}$, so from now on we denote the women reservation wage (match) as simply $T$.

Please observe that $W^{S}$, and therefore $T$ itself are both independent of men's search strategy $R_{i}$. This is because the two distributions of posted wages are exogenous: type $i$ men's reservation wage strategy does not affect $F_{i}($.$) , and nor does it affect the rate at which job searchers find wages that$ ensure the prospect of marriage. Finally, as one can see from (3), the measure of eligible men $\left(N_{i}\right)$ is also independent of $R_{i}$. 


\subsection{Men}

Unemployed single men face a decision problem that we term constrained job search. These men sample wage offers knowing that they can only get married if they land a wage at least as high as women's reservation match. With sequential search, a type $i$ unemployed single man uses an optimal stopping strategy that essentially boils down to having a reservation wage function $R_{i}(T)$. The shape of this best reply function is crucial for our analysis, and we show it has pretty robust characteristics.

As mentioned before, the more interesting and empirically relevant range is $T \in\left(\underline{R}_{i}, \bar{w}_{i}\right]$, where unemployed men are turned down by women. In contrast, employed single men could in principle be on wages that ensure marriageability.

Consider an unemployed single man of type $i$ who has just obtained an offer $w$. This wage makes him either marriageable or not marriageable. Denote by $V_{i}^{S}(w)$ the value of accepting such a job. Then, standard considerations mean that:

$$
V_{i}^{S}(w)=\left\{\begin{array}{lll}
\frac{w}{r+\delta}+\frac{\lambda n}{(r+\delta+\lambda n)(r+\delta)} y & \text { if } & w \geq T \\
\frac{w}{r+\delta} & \text { if } & w<T
\end{array}\right\}
$$

Clearly, the value of accepting an offer $w$ is a piecewise linear function: it is increasing in wage $w$ and is discontinuous at $w=T$.

Let $\bar{v}_{i}(w)$ be the expected value for a type $i$ unemployed man who currently has an offer $w$ that confers marriageability, and let $\underline{v}_{i}(w)$ denote the value of currently holding a wage offer that precludes marriage. This man has to decide whether to accept or reject such a job offer. Let $J_{i}$ denote the value that a type $i$ unemployed man attaches to the option of continued job search, and note that for any currently held wage offer $w$, this value $J_{i}$ is in fact independent of $w$.

Then, the corresponding two Bellman equations are:

$$
\bar{v}_{i}(w)=\max \left\{V_{i}^{S}(w \mid w \geq T), J_{i}\right\}
$$

and

$$
\underline{v}_{i}(w)=\max \left\{V_{i}^{S}(w \mid w<T), J_{i}\right\}
$$


Note that for $y>0$, we have $V_{i}^{S}(w \mid w \geq T)>V_{i}^{S}(w \mid w<T)$, and therefore $\bar{v}_{i} \geq \underline{v}_{i}$. The latter is with strict inequality if $V_{i}^{S}(w \mid w \geq T)>J_{i}$, which in turn is true for $T>\underline{R}_{i}$ (see the proof of Proposition 1 below).

Independently of a current wage offer $w$, and of course provided there is contact with another firm, continued job search leads to a new wage offer $w^{\prime}$. Given $F_{i}($.$) , the probability with which any such w^{\prime}$ is higher (or lower) than the female reservation wage (match) $T$ depends only on $T$ itself.

Importantly, all the above means that $J_{i}$ is a convex combination of $\bar{v}_{i}(w)$ and $\underline{v}_{i}(w)$ :

$$
J_{i}=\frac{\lambda_{0}}{r+\delta+\lambda_{0}}\left[\int_{T}^{\bar{w}_{i}} \bar{v}_{i}\left(w^{\prime}\right) d F_{i}\left(w^{\prime}\right)+\int_{\underline{w}_{i}}^{T} \underline{v}_{i}\left(w^{\prime}\right) d F_{i}\left(w^{\prime}\right)\right] .
$$

A given wage offer either confers marriageability or precludes the prospect of marriage. The right-hand side captures the discounted expected return to search: the terms in the big brackets describe the expected utility of any change in the value of a type $i$ unemployed man's state. Here, this is computed as the probability that he receives a wage offer $\left(\lambda_{0}\right)$, times the expected continuation value associated with the offer $w^{\prime}$, bearing in mind not only that an offer can of course be accepted or rejected, but also that if accepted, this wage then either guarantees or jeopardises completely one's marriage prospects.

The above continuation value $J_{i}$ is continuous for any $T<\bar{w}_{i}$, and is decreasing in $T$ for $\bar{v}_{i}>\underline{v}_{i}$. In contrast, $J_{i}$ is independent of $T$ for $T \geq \bar{w}_{i}$, since for such $T$ 's $F_{i}(T)=1$. With this in mind, let $\widehat{T}_{i}$ be the $T$ for which $J_{i}(T)=\frac{w}{r+\delta}$ at $w=T$. This particular female reservation match will prove extremely useful throughout our analysis below.

Making use of all the above, we are ready to fully characterise the male reservation wage function for any $T$.

Proposition 1 (A) For $T \in\left(\underline{R}_{i}, \bar{w}_{i}\right]$, the optimal strategy has the reservation property. The reservation wage function $R_{i}(T)$ solves

$$
R_{i}(T)=\min \left\{w: V_{i}^{S}(w) \geq J_{i}\right\},
$$

it is continuous and piecewise differentiable, with: 
(i) $R_{i}=T$ for $T \in\left(\underline{R}_{i}, \widehat{T}_{i}\right]$;

(ii) $R_{i}<T$ and decreasing in $T$ for $T \in\left(\widehat{T}_{i}, \bar{w}_{i}\right)$;

(B) For $T \leq \underline{R}_{i}$ and $T \geq \bar{w}_{i}$ the optimal strategy has the reservation property, and the reservation wage is $\underline{R}_{i}$.

Proof. Part (A). To address $(i)$, recall that $\widehat{T}_{i}$ is the $T$ for which $J_{i}(T)=\frac{w}{r+\delta}$ at $w=T$. If $T=\widehat{T}_{i}$, the optimal policy is a reservation wage $R_{i}$ and $R_{i}=T$ as $V_{i}^{S}(w \mid w<T)<J_{i}$ for $w<\widehat{T}_{i}$ and $V_{i}^{S}(w \mid w \geq T)>J_{i}$ for $w \geq \widehat{T}_{i}$. As $T$ decreases, $J_{i}(T)$ increases and $\frac{T}{r+\delta}$ decreases. For a small decrease in $T$, we have $J_{i}>V_{i}^{S}(w \mid w<T)$ and $J_{i}<V_{i}^{S}(w \mid w \geq T)$, so the reservation wage equals $T$. Let $\widetilde{T}_{i}$ denote the $T$ so low that $J_{i}\left(\widetilde{T}_{i}\right)=V_{i}^{S}\left(w \mid w=\widetilde{T}_{i}\right)$. It is easy to show that $\widetilde{T}_{i}<\underline{R}_{i}$, and therefore $V_{i}^{S}(w \mid w \geq T)>J_{i}$ for $T \in\left[\underline{R}_{i}, \widehat{T}_{i}\right]$. It follows that $R_{i}=T$ for $T \in\left(\underline{R}_{i}, \widehat{T}_{i}\right]$.

To address $(i i)$, start at $T=\widehat{T}_{i}$, where $\frac{T}{r+\delta}=J_{i}(T)$, and consider an increase in $T$. Then, $\frac{T}{r+\delta}$ increases and $J_{i}(T)$ decreases. Since the discontinuity in $V_{i}^{S}(w)$ moves rightward, it follows that $J_{i}=V_{i}^{S}(w \mid w<T)$ holds for a wage lower than $T$. This is our reservation wage $R_{i}$, which clearly decreases as $T$ increases. The derivation of both $R_{i}$ and $\widehat{T}_{i}$ are relegated to Appendix A, where we also show that given a finite $y$ and finite job offer arrival rate, the $R_{i}<T$ range always exists. One can also conclude that the optimal reservation wage is continuous in $T$, with a corner at $\widehat{T}_{i}$. Finally, for $T=\bar{w}_{i}$, we have $F_{i}(T)=1$ and the problem reverts to one of standard sequential job search.

Part (B). From (1), we know that once married, a type $i$ unemployed man drops his reservation wage to $\underline{R}_{i}$. Despite that, if $T \leq \underline{R}_{i}$ a woman would still be willing to marry such a man. Recall that $J_{i}^{M}=\frac{\underline{R}_{i}+y}{r+\delta}$ and let $J_{i}^{\prime}$ denote the value of a single unemployed man in this scenario. For any optimally chosen reservation wage $R_{i}^{\prime}$ that is higher than (or equal to) $T$ we have $V_{i}^{S}(w \mid w \geq T)$ for any acceptable offer, and $V_{i}^{S}(w \mid w \geq T)$ continuous in $w$. One can therefore write $J_{i}^{\prime}$ using the standard asset pricing equation:

$(r+\delta) J_{i}^{\prime}=\lambda n\left[J_{i}^{M}-J_{i}^{\prime}\right]+\lambda_{0} \int_{R_{i}^{\prime}}^{\bar{w}_{i}}\left[\frac{w}{r+\delta}+\frac{\lambda n}{(r+\delta)(r+\delta+\lambda n)} y-J_{i}^{\prime}\right] d F_{i}(w)$,

with the reservation wage $R_{i}^{\prime}$ solving $V_{i}^{S}\left(R_{i}^{\prime}\right)=J_{i}^{\prime}$. It is easy to show that $\underline{R}_{i}$ is indeed higher than $T$ and satisfies $V_{i}^{S}\left(\underline{R}_{i}\right)=J_{i}^{\prime}$, so $R_{i}^{\prime}=\underline{R}_{i}$.

Finally, for $T \geq \bar{w}_{i}$, we have $F_{i}(T)=1$ and the problem reverts to one of standard sequential job search. 
The reservation wage functions of unemployed men are illustrated in Figure 1. The diagram shows that men's best response functions are nonmonotonic and attain their respective maximum values at $T=\widehat{T}_{i}$, with $\widehat{R}_{i}$ $=R_{i}\left(\widehat{T}_{i}\right)=\widehat{T}_{i}$. Since $F_{H}(w)<F_{L}(w)$, we have that $\underline{R}_{L}<\underline{R}_{H}$ and $\widehat{T}_{H}>\widehat{T}_{L}$. Clearly, $\widehat{R}_{i}>\underline{R}_{i}$.

This non-monotonicity captures an interesting trade-off faced by all men, for different levels of $T$. When the marriage problem is non-trivial, an increase in the male reservation wage has two effects. On the one hand, it guarantees marriageability - if it satisfies women's reservation match. On the other hand, any increase in reservation wage comes at the cost of narrowing ones job prospects.

If the female reservation match is relatively low (but still above $\underline{R}_{i}$ ), the opportunity cost is not too high, and therefore men hold out for such a wage. However, this opportunity cost increases with $T$ and there is a threshold value $\left(\widehat{T}_{i}\right)$ for which the negative effect is no longer compensated by the prospect of marriage.

For $T \in\left(\widehat{T}_{i}, \bar{w}_{i}\right)$, we can show (see Appendix A) that the reservation wage solves:

$$
R_{i}=\frac{\lambda_{0}}{r+\delta}\left[\int_{R_{i}}^{\bar{w}_{i}}\left[1-F_{i}(w)\right] d w+\frac{\left[1-F_{i}(T)\right] \lambda n}{r+\delta+\lambda n} y\right] \quad(<T)
$$

By setting a reservation wage lower than what women expect, a single man risks throwing away the prospect of marriage. Nonetheless, he is willing to accept this gamble purely because of search frictions and what one might call the "bird in hand" effect. Now, a job offer is deemed acceptable by an unemployed single man even if it precludes marriage, given the relatively high threshold set by women. Nonetheless, such a wage may still be sufficiently high so that an unemployed turns down the option of holding out for even higher (but unlikely) offers.

For higher and higher female reservation matches the likelihood of encountering such increasingly high wages decreases further, since $1-F_{i}(T)$ decreases, and with it, men's reservation wage. Reservation wages gradually fall, to the point where men give up completely and rely on pure luck - after all, even the man who sets the lowest possible reservation wage may still be able to get married if he accidentally lands a good job. 


\subsection{Equilibrium with Marriage Premia}

A search equilibrium is a system $\left\{R_{i}, T, N_{i}, G_{i}(),. B_{i}, E_{i}(),. M_{i}\right\}$, where the reservation wage function is summarised in Proposition 1, $T$ is obtained from (7), while the various steady state measures of men, together with the distributions of earned wages result from inflow-outflow equations (2) - (6).

Recall that the marriage premium for type $i$ men $\left(M P_{i}\right)$ has been defined as the difference between the average wage earned by type $i$ married men and the average wage of type $i$ single men. Denoting the former by $\widetilde{w}_{i}^{M}$ and the latter by $\widetilde{w}_{i}^{S}$, we simply have $M P_{i} \equiv \widetilde{w}_{i}^{M}-\widetilde{w}_{i}^{S}$.

An equilibrium with zero marriage premium for all men is less relevant from an empirical point of view. Therefore, we focus on equilibria that exhibit a positive marital wage premium for at least one type. Crucially, such equilibria allow us to compare marriage premia across types.

Note that in the context of our model, to obtain a measurable marriage wage differential in the first place it must be true that at least some men can indeed get married. We work under the assumption that this is the case, so $T<\bar{w}_{i}$ for all $i$. Also, let $\widehat{T}_{H}<\bar{w}_{L}$ for now. Straight away, one can establish the link between reservation wages and marital wage differences.

Lemma $1 M P_{i}>0$ for $R_{i}<T$, and $M P_{i}=0$ for $R_{i}=T$.

Proof. Note that

$$
\widetilde{w}_{i}^{S}=\frac{B_{i}}{B_{i}+N_{i}} \int_{R_{i}}^{T} w d E_{i}(w)+\frac{N_{i}}{B_{i}+N_{i}} \int_{T}^{\bar{w}_{i}} w d G_{i}(w)
$$

and

$$
\widetilde{w}_{i}^{M}=\int_{T}^{\bar{w}_{i}} w d G_{i}(w) .
$$

For $T=R_{i}$, we have $B_{i}=0$ and $E_{i}(w)$ collapses to zero, so $\widetilde{w}_{i}^{M}=\widetilde{w}_{i}^{S}$. On the other hand, for $T>R_{i}$, we have $B_{i}>0$, and hence $\widetilde{w}_{i}^{M}>\widetilde{w}_{i}^{S}$.

Please note the importance of the above result: a positive marriage premium is possible only if the region where $R_{i}<T$ exists. In turn, as shown above, this can occur only when there are search frictions in the labour market. Obviously, marriage market search frictions are also needed if one is to talk about a meaningful reservation match $T$. 
Theorem 1 Let $\widehat{x}_{i}$ such that $T\left(\widehat{x}_{i}\right)=\widehat{T}_{i}$, $\underline{x}$ such that $T(\underline{x})=\underline{R}_{H}$, and $\bar{x}$ such that $T(\bar{x})=\bar{w}_{L}$.

Then, for $x \in[\underline{x}, \bar{x}]$, there always is a non-empty set of parameter values for which a unique equilibrium exists where only employed men can get married and both productivity types do. The potential equilibra are as follows:

(a) An equilibrium with $M P_{L}>M P_{H}>0$ obtains iff $x \in\left(\widehat{x}_{H}, \bar{x}\right)$;

(b) An equilibrium with $M P_{L}>M P_{H}=0$ obtains iff $x \in\left(\widehat{x}_{L}, \widehat{x}_{H}\right)$;

(c) An equilibrium with $M P_{i}=0$ obtains iff $x \in\left(\underline{x}, \widehat{x}_{L}\right)$.

Proof. We have established that $R_{H}$ and $R_{L}$ are continuous and nonmonotonic, and it is easy to show that $\underline{R}_{i}<\widehat{T}_{i}<\bar{w}_{i}$. Furthermore, we know that $T$ is independent of $R_{i}$. Together, these guarantee the existence of an unique equilibrium.

Since $\partial T / \partial x>0$ and $\underline{R}_{H}<\widehat{T}_{L}<\widehat{T}_{H}$, we have $\underline{x}<\widehat{x}_{L}<\widehat{x}_{H}<\bar{x}$. For $x \in[\underline{x}, \bar{x}]$, we have $\underline{R}_{i}<T<\bar{w}_{L}$ and therefore in an equilibrium only employed men can get married, and both $L$ and $H$ types do so as long as they earn a high enough wage.

For $\widehat{x}_{H}<x<\bar{x}$ we have $\widehat{T}_{H}<T<\bar{w}_{L}, R_{H}>R_{L}$ and $T>R_{i}$ for all $i$. From Lemma 1, $T>R_{i}$ implies there is a marriage premium for both types. Furthermore, $R_{H}>R_{L}$ means that, for a given $T$, the marriage premium is lower for $H$ type men.

For $\widehat{x}_{L}<x<\widehat{x}_{H}$ we have $\widehat{T}_{L}<T<\widehat{T}_{H}, R_{H} \gtreqless R_{L}, T>R_{L}$ and $T=R_{H}$. By Lemma $1, T>R_{L}$ implies that there is a marriage premium for $L$ type men but, as $T=R_{H}$, the $H$ types do not exhibit a marriage premium.

Finally, for $\underline{x}<x<\widehat{x}_{L}$ we have $\underline{w}_{H}<T<\widehat{T}_{L}$ and $R_{i}=T$. Using Lemma 1 again, this means no marriage wage premium for either type.

Figure 1 plots $T$ and $R_{i}$ and captures equilibrium $(a)$. The intersection point between the relevant best response functions captures the equilibrium where both productivity types exhibit (positive) male marriage wage premium.

\section{FIGURE 1 ABOUT HERE}

Theorem 1 contains very strong results which predict that the marriage premium among more productive men is lower than that among less productive men. Such an equilibrium outcome is possible (and hence observable) only if there are search frictions in the labour market, which are necessary for the non-monotonicity of the reservation wage function. 
For completeness, note that if $\widehat{T}_{H}>\bar{w}_{L}$, this only restricts the set of equilibria in which both types of men can marry in principle, but otherwise our qualitative results carry through. The full round-up of the potential equilibria in this case is relegated to Appendix B.

\section{Classes}

In what follows, we extend the model in three directions. First, we introduce a continuum of male types. Second, we consider female heterogeneity in the marriage market. Third, we also allow for the scenario where women are willing to marry unemployed men. These additional features allow for a richer set of results: male marriage premium patterns are now equilibrium outcomes that result not only from optimal constrained sequential job search, but also from a process of endogenous marital class formation.

To that end, assume that women are characterised by a measure of attractiveness $y$ in the marriage market. One can think of this as any non wage-related quality that is valued by men. Men rank potential marital partners identically, and let $y$ be distributed according to the cumulative distribution function $H(y)$ with support $[y, \bar{y}]$.

In turn, men are indexed by type $p$, and each type $p$ has a mass $u .^{6}$ Let $p$ take values between $p$ and $\bar{p}$. Men of type $p$ face an exogenous wage distribution $F_{p}($.$) with support [\underline{w}(p), \bar{w}(p)]$, with $\underline{w}(p)=p$ and $\bar{w}(p)=p+z$, where $z>0$. Another natural assumption is that $F_{p}(w)<F_{p^{\prime}}(w)$ for $p>p^{\prime}$. Given this, one can associate higher type $p$ with higher productivity.

Men and women choose reservation matches and subsequently marriage classes form endogenously. To keep the analysis simple, we construct an equilibrium with two classes only. That is, the population of men and women will endogenously divide into two sets: men from male Set 1 marry women from the female Set 1, and men from male Set 2 marry women from the female Set 2. Following that, Class 1 will contain highly desirable women paired up with very productive and/or high earning men, while Class 2 will have couples made up of less desirable women matched with less productive

\footnotetext{
${ }^{6}$ Having equal measures of each type amounts to having a uniform distribution of types, with density $\frac{1}{\bar{p}-\underline{p}}$.
} 
and/or low earning men. The reservation match strategies of men and women are derived in detail below, but for now, a quick overview is probably helpful.

Following our earlier analysis, men who ignore the marriage market (either because they can, or because they have no choice) set a reservation wage $\underline{R}(p)$.

Employed or unemployed men from Set 1 who are accepted by all women choose reservation match $y_{1}$. In turn, employed or unemployed men from Set 2 who are only accepted by women from female Set 2 choose reservation match $y_{2}$. These reservation values are such that $y_{1} \in[\underline{y}, \bar{y}]$ and $y_{2}<\underline{y}$. As we do not rule out unemployed men being able to get married, let $y^{*}(\bar{p})$ denote the reservation match of a type $p$ unemployed.

Similarly, the measure $n_{1}$ of Set 1 women choose reservation wage $T_{1}$, while women from Set 2 (measure $n_{2}$ ) choose reservation wage $T_{2}$. We limit our analysis to the case where $T_{1}<\bar{p}+z$, and note at this point that $n_{1}$ and $n_{2}$ are of course endogenously determined.

To keep the dynamics simple, we assume that a $y$ type woman is replaced by another woman of the same type whenever she gets married or exits the market. As a consequence, we can treat the total measure and distribution of single women as exogenous and are able to normalise it to 1 without any loss of generality. Hence, the measure of women in Set $1\left(n_{1}\right)$ is simply $\left[1-H\left(y_{1}\right)\right]$, while the measure of Set 2 women $\left(n_{2}\right)$ is $H\left(y_{1}\right)$.

Given the reservation wage strategies $R(p)$, as well as $\underline{R}(p), T_{1}$ and $T_{2}$ as defined above, the male population will split into groups, based on type and wage. More specifically, define threshold productivities $p_{1}, p_{2}, p_{3}$ such that:

$$
\begin{aligned}
& \underline{R}\left(p_{1}\right)=T_{1} \\
& \widehat{T}\left(p_{2}\right)=T_{1}
\end{aligned}
$$

and

$$
p_{3}=T_{1}-z
$$

Then, we we obtain the following groups of men:

(i) Men with $p \in\left[p_{1}, \bar{p}\right]$ can afford not to care about the marriage market. These men can marry anyone, even when unemployed, and for them it is also true that $y^{*}=y_{1}$. 
(ii) Men with $p \in\left[p_{2}, p_{1}\right)$ set $R(p)=T_{1}$ because $\widehat{T}\left(p_{2}\right)=T_{1}$. These men can - once they get a job - marry women from Set 1 . While unemployed, they may be willing to marry a woman from Set 2 if her $y$ is high enough: that is, higher than $y^{*}(p)$.

(iii) Men with $p \in\left[p_{3}, p_{2}\right)$ will chance it in the sense that they set $R(p)<$ $T_{1}$. If they are lucky and land a wage $w \geq T_{1}$, they subsequently have access to women from Set 1.

(iv) Men below $p_{3}$ can not hope to marry women from Set 1 , since a $p_{3}$ type man has $\bar{w}\left(p_{3}\right)=T_{1}$. Their only chance is women from Set 2 . Note that for these men to exist, we require that $\underline{p}<p_{3}$, so we work under this scenario.

Next, define $p^{*}$ such that a Set 2 woman is indifferent between staying single or marrying an unemployed $p^{*}$ man. With $p^{*}<p_{3}$, Set 2 women are willing to marry at least some men with $p<p_{3}$. Indeed, if $p^{*}<\underline{p}$, Set 2 women will in fact marry all unemployed men with $p<p_{3}$. As we will see, this condition ensures there is a second class in which some male types (those with $p<p_{3}$ ) have zero marriage wage premium.

Please note that constructing such a bottom class is by no means trivial. Firstly, this is because both $p^{*}$ and $p_{3}$ are in fact endogenous. Secondly, women from Set 2 could in principle find partners from three groups of single men: those with $p \in\left[p, p_{3}\right)$, those with $p \in\left[p_{3}, p_{2}\right)$ who are chancing it and are either unemployed or unlucky, as well as those who, while holding out for a wage that ensures marriageability to a Set 1 woman, may nonetheless be willing to marry some Set 2 women instead. Indeed, a Set 2 woman with attractiveness $y$ will be accepted by men with productivity no higher than $p^{\prime}$, where $p^{\prime} \in\left[p_{2}, p_{1}\right)$ is defined as the productivity $p$ for which $y^{*}(p)=y$.

\subsection{Search}

In this section we characterise the optimal reservation wage and/or match strategy for men, together with the optimal reservation match strategy for women. We assume $\bar{p}<T_{1}<\bar{p}+z$. 


\subsubsection{Men}

Employed men with $w \geq T_{1}$ These are single men with $p \in\left[p_{3}, \bar{p}\right]$, and the pool contains those who are very high type (so can ignore the marriage market), those who held out for a wage no lower than $T_{1}$, and those who chanced it but were lucky and obtained a marriageable wage. Having access to all women, these men only accept women with $y \geq y_{1}$.

Let $V_{1}^{S}(w)$ denote their value of being single and employed at wage $w \geq$ $T_{1}$, and $V^{M}(w, y)$ denote their value of being married to a type $y$ woman. Then, $V^{M}(w, y)=\frac{w+y}{r+\delta}$ and:

$$
(r+\delta) V_{1}^{S}(w)=w+\lambda n_{1} \int_{y_{1}}^{\bar{y}}\left[V^{M}(w, y)-V_{1}^{S}(w)\right] d H^{\prime}(y),
$$

where:

$$
H^{\prime}(y)=\frac{H(y)-H\left(y_{1}\right)}{1-H\left(y_{1}\right)} \quad \text { and } \quad n_{1}=1-H\left(y_{1}\right) .
$$

The interpretation is straightforward: a single man who earns a wage $w$ meets a desirable woman from Set 1 at rate $\lambda n_{1}$ and gets married. Alternatively, one can rewrite the above as:

$$
V_{1}^{S}(w)=\frac{w}{r+\delta}+\frac{\lambda}{\left[r+\delta+\lambda\left(1-H\left(y_{1}\right)\right)\right](r+\delta)} \int_{y_{1}}^{\bar{y}} y d H(y)
$$

From the definition of a reservation match, we have:

$$
V^{M}\left(w, y_{1}\right)=V_{1}^{S}(w)
$$

Using this, we obtain:

$$
y_{1}=\frac{\lambda}{r+\delta} \int_{y_{1}}^{\bar{y}}[1-H(y)] d y
$$

The interpretation is standard, as the right-hand side reflects the opportunity cost of continued search in the marriage market. 
Employed men with $w<T_{1}$ These are single men with $p \in\left[\underline{p}, p_{2}\right)$, and the group includes men with $p \in\left[p_{3}, p_{2}\right)$ - those who chanced it but were unlucky and ended up with an unappealing wage, as well as those with $p<p_{3}$ - men who were hopeless to start with. All these men can only marry women with attractiveness $y$ lower than $y_{1}$. By construction, they will accept them all, so there is no third class. This means that $V^{M}(w, y) \geq V_{2}^{S}(w)$, where $V_{2}^{S}(w)$ denotes the value of being single for these men, obtained from:

$$
(r+\delta) V_{2}^{S}(w)=w+\lambda n_{2} \int_{y_{2}}^{y_{1}}\left[V^{M}(w, y)-V_{2}^{S}(w)\right] d H^{\prime \prime}(y)
$$

where:

$$
H^{\prime \prime}(y)=\frac{H(y)}{H\left(y_{1}\right)} \quad \text { and } \quad n_{2}=H\left(y_{1}\right)
$$

Alternatively, we can write:

$$
V_{2}^{S}(w)=\frac{w}{r+\delta}+\frac{\lambda}{\left[r+\delta+\lambda H\left(y_{1}\right)\right](r+\delta)} \int_{\underline{y}}^{y_{1}} y d H(y)
$$

Again, equating $V_{2}^{S}(w)$ and $V^{M}\left(w, y_{2}\right)$, one obtains the reservation match implicitly:

$$
y_{2}=\frac{\lambda}{r+\delta} \int_{y_{2}}^{y_{1}}\left[H\left(y_{1}\right)-H(y)\right] d y
$$

Given the above, in order to satisfy $y_{2}<\underline{y}$, we need:

$$
\underline{y}>\frac{\lambda}{r+\delta+\lambda H\left(y_{1}\right)} \int_{\underline{y}}^{y_{1}} y d H(y)
$$

Unemployed men These are single men who choose a reservation match $y^{*}(p)$ in the marriage market as well as a reservation wage $R(p)$ in the labour market.

From our previous analysis of the constrained sequential job search problem, we know there are two important ranges of relevant reservation wages. 
(a) Unemployed men with $p \in\left[p_{2}, p_{1}\right)$ who choose $R(p)=T_{1}$.

Recall that as soon as any unemployed gets married, he subsequently sets $R(p)$ equal to $\underline{R}(p)$. As a consequence, Set 1 women do not marry them in the first place. Nonetheless, while unemployed, these men do set a reservation match $y^{*}(p)$ which may or may not be lower than $y_{2}$.

Denote the value of unemployment of these men by $U_{1}(p)$, and also note that, once they find a wage higher than or equal to $T_{1}$, their value of unemployment is lower than the value of employment: $U_{1}(p)<\frac{T_{1}}{(r+\delta)}$. After finding such a wage, their reservation match is set at $y_{1}$ and therefore while unemployed, their reservation match $y^{*}(p)$ must be less than $y_{1}$.

Since unemployed men drop their reservation wage to $\underline{R}(p)$ after marriage, their value of being jobless but married is:

$$
V^{M}(\underline{R}(p), y)=\frac{\underline{R}(p)+y}{r+\delta}
$$

The discounted lifetime utility of being married while unemployed reflects the fact that once a man gets married his reservation wage drops to $\underline{R}(p)$.

In turn, their value of being unemployed is:

$$
\begin{gathered}
(r+\delta) U_{1}(p)=\lambda_{0}\left[1-F_{p}\left(T_{1}\right)\right] \int_{T_{1}}^{\bar{w}(p)}\left[V_{1}^{S}(w)-U_{1}(p)\right] d F_{p}\left(w \mid w>T_{1}\right)+ \\
+\lambda n_{2}\left[H\left(y_{1}\right)-H\left(y^{*}(p)\right)\right] \int_{y^{*}(p)}^{y_{1}}\left[V^{M}(\underline{R}(p), y)-U_{1}(p)\right] d H\left(y \mid y_{1}>y>y^{*}(p)\right)
\end{gathered}
$$

As mentioned, these unemployed men are not acceptable to Set 1 women. Nonetheless, they can of course look for a job and only accept it if the wage offered is above $T_{1}$ - in which case they become marriageable to Set 1 women. Alternatively, they could meet a Set 2 woman who will accept them despite the fact that they are unemployed. However, these men will only accept such women if in turn they have a sufficiently high $y$. This particular reservation match $y^{*}(p)$ solves:

$$
V^{M}\left(\underline{R}(p), y^{*}(p)\right)=U_{1}(p)
$$


From the definition of a reservation wage, a jobless man is indifferent between continued job search while single and marriage to a $y^{*}$

Next, using $V_{1}^{S}(w)=V^{M}\left(w, y_{1}\right)$ together with $U_{1}(p)=V^{M}\left(\underline{R}(p), y^{*}(p)\right)$, and integrating by parts, we obtain $y^{*}$ implicitly: ${ }^{7}$

$$
\begin{aligned}
y^{*}(p)= & \frac{\lambda_{0}}{r+\delta} \int_{T_{1}}^{\bar{w}(p)}\left[1-F_{p}(w)\right] d w+ \\
& +\frac{\lambda_{0}}{r+\delta}\left[1-F_{p}\left(T_{1}\right)\right]\left[y_{1}-y^{*}(p)\right]+ \\
& +\frac{\lambda n_{2}}{r+\delta} \int_{y^{*}(p)}^{y_{1}}\left[H\left(y_{1}\right)-H(y)\right] d y-\underline{R}(p)
\end{aligned}
$$

The male reservation match has to compensate for: $(i)$ the standard option of continued search for better wages while unemployed; $(i i)$ the possibility of an utility gain (in terms of $y$ ) from potentially finding a wage higher than $T_{1}$ that allows a partnership with a Set 1 woman; and (iii) the option of continued search for women with higher $y$. These three effects are mitigated by the option of dropping the reservation wage to $\underline{R}(p)$ if in the position to get married while unemployed.

We can further characterise this reservation match $y^{*}(p)$. First, a simple implicit derivation of the $y^{*}$ equation shows that $\partial y^{*}(p) / \partial p>0$. Second, one can show that if $y_{2} \leq y$, then $y^{*}(p) \leq y$ for $p \in\left(p_{3}, p_{2}\right]$. To see this, consider men with $p \in\left(p_{3}, p_{2}\right)$. Denote their value of unemployment by $U_{2}(p)$, and observe that $V_{2}^{S}=\frac{R(p)}{r+\delta}=U_{2}(p)$. If $y_{2}$ is their reservation match while employed (that is, when enjoying utility $V_{2}^{S}$ ), then it is also $y_{2}$ while jobless (that is, when enjoying utility $U_{2}(p)=V_{2}^{S}$ ).

Note that in principle, $y^{*}(p)$ can be higher or less than $y$. To explore this further, define $p^{\prime}$ such that $y^{*}\left(p^{\prime}\right)=y$. From the above, we know that $p^{\prime}>p_{2} \cdot{ }^{8}$ For $p^{\prime}>p_{1}$, all men with $p \in\left(p_{2}, p_{1}\right)$ set $y^{*}(p)<y$ and are willing to

\footnotetext{
${ }^{7}$ We present the implicit version as it has a more intuitive interpretation, but note that $y^{*}(p)$ can easily be derived explicitly.

${ }^{8}$ For $p=p_{2}$ we have $R\left(p_{2}, T_{1}\right)=T_{1}$, so it is true that $V_{1}^{s}\left(R\left(p_{2}\right)\right)=\frac{R\left(p_{2}\right)}{r+\delta}=U\left(p_{2}\right)$. The reservation match of these men is $y_{2}<\underline{y}$.
} 
marry all women. For $p^{\prime}<p_{1}$, men with $p \in\left(p_{2}, p^{\prime}\right)$ also set $y^{*}(p)<\underline{y}$, while men with $p \in\left(p^{\prime}, p_{1}\right)$ set $y^{*}(p)>y$ and only accept women with $y>y^{*}\left(p^{\prime}\right)$, where $y^{*}\left(p^{\prime}\right)>\underline{y}$.

(b) Unemployed men with $p \in\left[p_{3}, p_{2}\right)$ who choose $R(p)<T_{1}$.

These men are willing to accept wages that put them in the male Set 2 . Of course, they may still be lucky and find wages that get them into Set 1, giving access to Set 1 women. Their value of unemployment is $U_{2}(p)$, where $(r+\delta) U_{2}(p)=$

$$
\begin{gathered}
\lambda_{0}\left[F_{p}\left(T_{1}\right)-F_{p}(R(p))\right] \int_{R(p)}^{T_{1}}\left[V_{2}^{S}(w)-U_{2}(p)\right] d F_{p}\left(w \mid R(p)<w<T_{1}\right)+ \\
+\lambda_{0}\left[1-F_{p}\left(T_{1}\right)\right] \int_{T_{1}}^{\bar{w}(p)}\left[V_{1}^{S}(w)-U_{2}(p)\right] d F_{p}\left(w \mid w>T_{1}\right)+ \\
+\lambda n_{2} \int_{\underline{y}}^{y_{1}}\left[V^{M}(\underline{R}(p), y)-U_{2}(p)\right] d H\left(y \mid y<y_{1}\right)
\end{gathered}
$$

These men could: $a$ ) accept a wage less than $T_{1}$ that puts them in Set 2 , $b$ ) find a job that puts them in Set 1, or $c$ ) find an acceptable Set 2 woman and get married. The latter implies that for these men, $y^{*}(p) \leq y$ : jobless or not, they find Set 2 women desirable. Having accepted $R(p)$, they set $y^{*}(p) \leq y$, and they are indifferent between unemployment and employment at wage $\bar{R}(p)$.

Once again, recall that if a jobless man gets married, subsequently his reservation wage drops to $\underline{R}(p)$. Hence, the value of being married while unemployed is again $V^{M}(\underline{R}(p), y)=\frac{R(p)+y}{(r+\delta)}$. From the definition of a reservation wage, and using $V_{1}^{S}(w)$ and $V_{2}^{S}(w)$, as well as $n_{2}=H\left(y_{1}\right)$, we obtain: 


$$
\begin{aligned}
R(p) & =\frac{\lambda_{0}}{r+\delta+\lambda H\left(y_{1}\right)} \int_{R(p)}^{\bar{w}(p)}\left[1-F_{p}(w)\right] d w+ \\
& +\frac{\lambda_{0}(r+\delta)}{r+\delta+\lambda H\left(y_{1}\right)}\left[1-F_{p}\left(T_{1}\right)\right]\left[V_{1}^{S}(w)-V_{2}^{S}(w)\right]+ \\
& +\frac{\lambda}{r+\delta+\lambda H\left(y_{1}\right)} \int_{\underline{y}}^{y_{1}}[\underline{R}(p)+y] d H(y) \quad\left(<T_{1}\right) .
\end{aligned}
$$

The terms on the right hand side reflect that the reservation wage has to compensate for: $(i)$ the standard option of continued search for better wages, $(i i)$ the foregoing of the potential to marry a Set 1 woman (and the acceptance of only being able to marry Set 2 women), as well as (iii) the option of marrying a Set 2 woman while unemployed.

(c) Unemployed men with $p \in\left[p_{1}, \bar{p}\right]$ and unemployed men with $p \in\left[\underline{p}, p_{3}\right)$.

Recall that $p_{1}$ is such that $\underline{R}\left(p_{1}\right)=T_{1}$. Therefore, men with $p>p_{1}$ need not worry about marriage, since $\underline{R}(p)>T_{1}$, so they set their reservation wage equal to $\underline{R}(p)$.

\subsubsection{Women}

Women in Set 1 These women only marry men whose wages are higher than $T_{1}$. The pool of such eligible singles is made up of the following:

i) a measure $N_{p}$ of single employed men with $p>p_{1}$, whose wages are higher than $T_{1}$;

ii) a measure $u\left[\bar{p}-p_{1}\right]$ of single unemployed men with $p>p_{1}$, who have reservation wages $\underline{R}(p)>T_{1}$;

iii) a measure $N_{p}^{\prime}$ of single employed men with $p \in\left[p_{2}, p_{1}\right)$, who have held out for a wage at least as high as $T_{1}$;

$i v$ ) a measure $N_{p}^{\prime}$ of single employed men with $p \in\left[p_{3}, p_{2}\right)$, who chanced it, were lucky and are now earning a wage $w \geq T_{1} \cdot{ }^{9}$

\footnotetext{
${ }^{9}$ The last two measures are equal because the wage distributions are exogenous.
} 
Using steady-state equations analogous to the ones in Section 3, we obtain the measures and distribution of earned wages for eligible men ${ }^{10}$ :

$$
\begin{gathered}
G_{p}(w)=\frac{F_{p}(w)-F_{p}\left(T_{1}\right)}{1-F_{p}\left(T_{1}\right)} \\
N_{p}=\frac{u \lambda_{0}\left[1-F_{p}(\underline{R}(p))\right]}{\lambda n_{1}+\delta} \\
N_{p}^{\prime}=\frac{u \lambda_{0}\left[1-F_{p}\left(T_{1}\right)\right]}{\lambda n_{1}+\delta}
\end{gathered}
$$

Given the above, for a woman in Set 1 the value of being single is:

$$
\begin{aligned}
(r+\delta) W_{1}^{S}= & \Psi \int_{p_{1}}^{\bar{p}} N_{p}\left[\int_{\underline{\underline{R}(p)}}^{\bar{w}_{p}}\left(\frac{w}{r+\delta}-W_{1}^{S}\right) d G_{p}(w)\right] d p+ \\
& +\Psi u\left[\bar{p}-p_{1}\right] \int\left[\frac{\underline{R}(p)}{r+\delta}-W_{1}^{S}\right] d p+ \\
& +\int_{p_{1}}^{\min \left(p_{1}, \bar{p}\right)} N_{p}^{\prime}\left[\int_{T_{1}}^{\bar{w}_{p}}\left(\frac{w}{r+\delta}-W_{1}^{S}\right) d G_{p}(w)\right] d p+ \\
& +\int_{p_{3}}^{\min \left(p_{2}, \bar{p}\right)} N_{p}^{\prime}\left[\int_{T_{1}}^{\bar{w}_{p}}\left(\frac{w}{r+\delta}-W_{1}^{S}\right) d G_{p}(w)\right] d p
\end{aligned}
$$

where $\Psi=1$ for $\bar{p}>p_{1}$ and $\Psi=0$ otherwise.

From the above, and using the definition of a reservation wage $W_{1}^{S}=\frac{T_{1}}{r+\delta}$, we obtain $T_{1}$ implicitly:

\footnotetext{
${ }^{10}$ The steady state measures of bachelors $\left(B_{p}\right)$ and married men $\left(M_{p}\right)$, together with their respective distributions of earned wages are obtained from inflow-outflow equations similar to the ones in Section 3.
} 


$$
\begin{aligned}
{\left[r+\delta+u\left(\bar{p}-p_{1}\right)\right] \frac{T_{1}}{r+\delta}=} & \int_{p_{1}}^{\bar{p}}\left[\frac{u \lambda_{0}}{\left(\lambda n_{1}+\delta\right)(r+\delta)} \int_{\underline{R}(p)}^{\bar{w}_{p}}\left[1-F_{p}(w)\right] d w\right] d p+ \\
= & \\
& +\Psi u\left(\bar{p}-p_{1}\right) \int_{p_{1}}^{\bar{p}} \frac{\underline{R}(p)}{r+\delta} d p+\int_{p_{2}}^{\bar{w}_{p}} \\
& +\int_{T_{1}}^{\min \left(p_{1}, \bar{p}\right)}\left[\frac{u \lambda_{0}}{\left(\lambda n_{1}+\delta\right)(r+\delta)} \int_{T_{1}}\left[1-F_{p}(w)\right] d w\right] d p+ \\
& +\int_{p_{p}}^{\min \left(p_{2}, \bar{p}\right)}\left[\frac{u \lambda_{0}}{\left(\lambda n_{1}+\delta\right)(r+\delta)} \int_{T_{1}}\left[1-F_{p}(w)\right] d w\right] d p
\end{aligned}
$$

Women in Set 2 These women have no access to Set 1 men. As a consequence (and allowing for $\underline{p} \lessgtr p^{*}$ ), a Set 2 woman with attractiveness $y$ will only accept a man from the following pool:

i) a measure $N_{p}^{\prime \prime}$ of single and employed men with $p \in\left[p_{3}, \min \left(p_{2}, \bar{p}\right)\right]$ who chanced it but were unlucky and now earn $w<T_{1}$;

ii) a measure $u\left[p_{3}-\max \left(\underline{p}, p^{*}\right)\right]$ of single unemployed men with $p \in$ $\left[\max \left(\underline{p}, p^{*}\right), p_{2}\right)$ who - while unemployed - cannot marry Set 1 women. These are men who are yet to find a job: men with $p_{3}<p<p_{2}$ who are chancing it, or men with $p>p_{2}$ who set their reservation wage equal to $T_{1}$;

iii) a measure $u\left[\left(p^{\prime}(y)-p_{2}\right]\right.$ of single unemployed men with $p \in\left[p_{2}, p^{\prime}(y)\right]$, whith $p^{\prime}(y)$ being the productivity $p$ for which $y^{*}(p)=y$. These are men who - while unemployed - are once again refused by Set 1 women, and whose productivity is low enough so they accept a woman with attractiveness $y$.

Note that $p^{*}$, as previously defined, is obtained implicitly from $\frac{R\left(p^{*}\right)}{r+\delta}=$ $W_{2}^{S}$. The steady state measure $N_{p}^{\prime \prime}$ and the $G^{\prime}(w)$ distribution of wages earned by these men are obtained from the straightforward steady state equations: 


$$
u \lambda_{0}\left[F_{p}(w)-F_{p}(R(p))\right]=G_{p}^{\prime}(w) N_{p}^{\prime \prime}\left(\delta+\lambda n_{2}\right)
$$

and

$$
u \lambda_{0}\left[F_{p}\left(T_{1}\right)-F_{p}(R(p))\right]=N_{p}^{\prime \prime}\left(\delta+\lambda n_{2}\right) .
$$

Thus, we obtain:

$$
G_{p}^{\prime}(w)=\frac{F_{p}(w)-F_{p}(R(p))}{F_{p}\left(T_{1}\right)-F_{p}(R(p))}
$$

and

$$
N_{p}^{\prime \prime}=\frac{u \lambda_{0}\left[F_{p}\left(T_{1}\right)-F_{p}(R(p))\right]}{\delta+\lambda n_{2}}
$$

With $p^{*}<p_{3}$, and given the relevant combined pool of single men, the value of being single for a Set 2 woman is therefore:

$$
\begin{aligned}
(r+\delta) W_{2}^{S}(y)= & \int_{p_{3}}^{\min \left(p_{2}, \bar{p}\right)} N_{p}^{\prime \prime} \int_{R(p)}^{T_{1}}\left[\frac{w}{r+\delta}-W_{2}^{S}\right] d G_{p}^{\prime}(w) d p+ \\
& +u\left[p_{3}-\max \left(\underline{p}, p^{*}\right)\right] \int_{\max \left(\underline{p}, p^{*}\right)}^{p_{3}}\left[\frac{\underline{R}(p)}{r+\delta}-W_{2}^{S}\right] d p+ \\
& +\Omega u\left[\left(p^{\prime}(y)-p_{2}\right] \int_{p_{2}}^{p^{\prime}(y)}\left[\frac{\underline{R}(p)}{r+\delta}-W_{2}^{S}\right] d p,\right.
\end{aligned}
$$

where $\Omega=1$ for $p^{\prime}(y)>p_{2}$ and $\Omega=0$ otherwise.

Note that $p^{*}>\underline{p}$ implies that $\frac{R\left(p^{*}\right)}{r+\delta}=W_{2}^{S}$, and therefore $T_{2}=\underline{R}\left(p^{*}\right)$. On the other hand, for $p^{*}<\underline{p}$, we have $W_{2}^{S}>\frac{R\left(p^{*}\right)}{r+\delta}\left(=\frac{T_{2}}{r+\delta}\right)$.

\subsection{Equilibrium with classes}

Below, we first define an equilibrium with two classes, where the bottom class is characterised by zero marriage premium. This is essentially a summary of the best response strategies and steady-state variables derived in the previous section. Following that, we discuss the necessary existence conditions, and 
show (using a numerical solution) that such an equilibrium indeed exists. We also generalise our main qualitative result to any number of classes. Finally, we provide a full characterisation of possible marriage premia patterns across male productivity types as well as marriage classes.

Given the definition of $p_{1}, p_{2}, p_{3}$, and together with steady-state measures of various men and women, as well as earned wages, a steady-state search equilibrium with two classes is essentially a system:

$$
\left\{T_{1}, T_{2}, \underline{R}(p), R(p), y_{1}, y_{2}, y^{*}(p), p^{*}\right\}
$$

such that:

(i) Women's reservation matches satisfy:

$$
T_{1}=(r+\delta) W_{1}^{S}(w)
$$

and

$$
\begin{aligned}
& T_{2}=\underline{R}\left(p^{*}\right) \text { for } p^{*}>\underline{p}, \quad \text { or } \\
& T_{2}<(r+\delta) W_{2}^{S}(w) \text { for } p^{*}<\underline{p},
\end{aligned}
$$

where $W_{j}^{S}(w)$ as defined (with $j=1,2$ ).

(ii) Type $p$ unemployed men's reservation wages and reservation matches depend on whether or not they take the marriage market into account:

(a) If they ignore the marriage market:

$$
\underline{R}(p)=\frac{\lambda_{0}}{r+\delta} \int_{\underline{R}(p)}^{\bar{w}_{p}}\left[1-F_{p}(w)\right] d w
$$

(b) If they take the marriage market into account:

$$
\begin{aligned}
R(p)= & T_{1} \quad \text { and } \\
y^{*}(p)= & \frac{\lambda_{0}}{r+\delta} \int_{T_{1}}^{\bar{w}(p)}[1-F(w)] d w+\frac{\lambda_{0}}{r+\delta}\left[1-F_{p}\left(T_{1}\right)\right]\left[y_{1}-y^{*}(p)\right]+ \\
& +\frac{\lambda n_{2}}{r+\delta} \int_{y^{*}(p)}^{y_{1}}\left[H\left(y_{1}\right)-H(y)\right] d y-\underline{R}(p)
\end{aligned}
$$


or

$$
\begin{aligned}
R(p) & =\frac{\lambda_{0}}{r+\delta+\lambda H\left(y_{1}\right)} \int_{R(p)}^{\bar{w}(p)}\left[1-F_{p}(w)\right] d w+ \\
& +\frac{\lambda_{0}(r+\delta)}{r+\delta+\lambda H\left(y_{1}\right)}\left[1-F\left(T_{1}\right)\right]\left[V_{1}^{S}(w)-V_{2}^{S}(w)\right]+ \\
& +\frac{\lambda}{r+\delta+\lambda H\left(y_{1}\right)} \int_{\underline{y}}^{y_{1}}[\underline{R}(p)+y] d H(y) \quad\left(<T_{1}\right) .
\end{aligned}
$$

(iii) Employed men's reservation matches are:

$$
y_{1}=\frac{\lambda}{r+\delta} \int_{y_{1}}^{\bar{y}}[1-H(y)] d y \quad \text { if } w \geq T_{1}
$$

and

$$
y_{2}=\frac{\lambda}{r+\delta} \int_{y_{2}}^{y_{1}}\left[H\left(y_{1}\right)-H(y)\right] d y \quad \text { if } w<T_{1} .
$$

(iv) Threshold male type $p^{*}$ satisfies:

$$
\frac{\underline{R}\left(p^{*}\right)}{r+\delta}=W_{2}^{S}
$$

\subsubsection{Existence and characterisation:}

Theorem 2 The set of parameters for which a two-class search equilibrium with zero male marriage premium in the bottom class exists is non-empty. Such an equilibrium exhibits $p^{*}<p_{3}$, and exists if $p^{*}<\underline{p}<p_{3}$ and $\underline{y}>\underline{y^{\prime}}$, where $\underline{y}^{\prime}=y_{2}\left(\underline{y}^{\prime}\right)$.

Proof. All choice variables are continuous, and the equilibrium equations are twice-differentiable. To show existence, it is enough to provide a numerical solution and find a set of such equilibrium parameters (see Appendix C).

To characterise this equilibrium, first assume that $p^{*}>p_{3}$. Then, all men in Set 2 - those with $p \in\left(p^{*}, p_{3}\right)$ - will chance it, so for these men the marriage 
premium is positive. Some males (those with $p<p^{*}$ ) would constitute a third set of men, but they would never marry.

The condition $y>y^{\prime}$ simply says that Set 2 men are willing to marry all women not in Set 1, so there is no third female set. These women make up Set 2, which is therefore also the bottom set. Note that $y_{2}$ is positive and independent of $\underline{y}$ when $\underline{y}<y_{2}$. In addition, $y_{2}$ is increasing in $\underline{y}$ when $\underline{y}>y_{2}$. Hence, $\underline{y}^{\prime}>0$, and therefore it is always possible to choose a $\underline{y} \in\left(\underline{y^{\prime}}, y_{1}\right)$ such that $y>y_{2}$. Consequently, set 2 men are willing to marry all women not in Set 1 , which makes Set 2 the only other (bottom) female set. This also rules out a third class.

Next, assume that $p>p_{3}$, so even the lowest type men chance it. But then there is always a positive marriage premium. Instead, assume $p<p_{3}$. This implies $T_{1}>\underline{R}(p)$, and hence set 1 women reject some men. In particular, a set 1 woman will never marry an unemployed of type $p_{3}$, or indeed any unemployed of even lower type. From the equation for $T_{1}$ it is clear that $T_{1}<\bar{p}+z$ as long as $\lambda$ is not infinite. Since $p_{3}=T_{1}-z$, we have $\bar{p}>p_{3}$. This ensures that there are unemployed men who chance it, and hence it rules out a one-class equilibrium. Note that $\bar{p}<p_{3}$ would mean that all unemployed men ignored $T_{1}$, which would then make this $T_{1}$ sub-optimal for women. Women would set a lower reservation match, and this lower $T_{1}$ would in turn lead to the existence of additional sets of men. Since $\partial p_{3} / \partial p=0$ for $p<p_{3}$, one can always choose a low enough $p$ which satisfies the above condition. Together with $p^{*}<p$, this ensures that the second class is in fact the bottom class, as there are only two sets of each gender. Finally, $p^{*}<\underline{p}$ also implies that Set 2 women marry all Set 2 men, even if these men are unemployed, meaning zero marriage premium.

Figure 2 below illustrates a search equilibrium with two marital classes and associated marriage premium patterns:

\section{FIGURE 2 ABOUT HERE}

For reasons of tractability, so far we have only focused on a two-class search equilibrium. However, this is without any loss of generality, either in terms of endogenous class formation ${ }^{11}$ or in terms of having a zero marriage premium for men in a bottom class - that is, bottom among any number of classes. Indeed, we have the following result:

\footnotetext{
${ }^{11}$ As shown by Burdett and Coles (1997).
} 
Corollary 1 Let $K$ be the number of marriage classes and let $p_{K}^{*}$ defined by $\underline{R}\left(p_{K}^{*}\right)=T_{K}$. In any search equilibrium with $K$ classes, $p_{K}^{*}<T_{K}-z$ and the men in the bottom class have zero marriage premium.

Proof. Assume $K$ classes. Then, any equilibrium with $p_{K}^{*}<T_{K}-z$ is such that $M P=0$ amongst some men in the $K^{\text {th }}$ class, simply because $\underline{p}$ can always be chosen such that $p^{*}<\underline{p}<p_{3}$. With two classes, $p_{K}^{*}<T_{K}-z$ is actually $p^{*}<T_{1}-z=p_{3}$.

\subsubsection{Marriage premia across productivities and classes}

Finally, we summarise the marriage premia patterns pertaining to men of various productivities as well as across classes in a two-class equilibrium.

(A) Men with extremely high productivity $\left(p>p_{1}\right.$, for whom $\underline{R}(p)>$ $T_{1}$ ) can ignore the labour market. They qualify for male Set 1 even when unemployed. As a consrquence, they only marry women with $y>y_{1}$ and form Class 1 partnerships with such Set 1 women. The marriage premium of these men is zero, due to the fact that labour market status is simply irrelevant for their prospects in the marriage market.

(B) Highly productive men (with $p_{2} \leq p<p_{1}$ ) will not accept wages that put them in Set 2. They choose $R(p)=T_{1}$. If (and only if) they find such an acceptable wage, they are able to marry Set 1 women and form Class 1 partnerships with them. There is no marriage wage premium associated with marriage to Set 1 women. However, there is a marriage wage penalty associated with marriage to Set 2 women. Recall that although these men only accept wages that put them in Set 1, while unemployed they belong to the male Set 2 , as only Set 2 women accept them. Given this, they could end up marrying a Set 2 woman who has a high enough $y$. Following that, however, their reservation wage goes down to $\underline{R}(p)$, which in turn generates the marriage penalty.

$(C)$ Mid-productivity men (with $p_{3} \leq p<p_{2}$ ) choose $R(p)<T_{1}$, and are therefore willing to accept wages that put them in male Set 2. Despite that, they can be lucky and still find a wage that puts them in male Set 1 . In that case, there is a positive marriage premium associated with marrying Set 1 women and forming Class 1 couples. In contrast, marriage to a Set 2 
woman leads to a marriage penalty. However, note that this penalty is lower than that of the highly productive men discussed above. This is because this earnings penalty pertains to employed men with wages between $R(p)$ and $T_{1}$ : these men find a job first, and only after that, a Set 2 female partner. This is in addition to those men who find a Set 2 partner first, subsequently drop their reservation wage to $\underline{R}(p)$ and then find a job.

$(D)$ Low productivity men can find themselves in two situations:

(i) if $p^{*}<p<p_{3}$, the highest available wage for those having $p \in$ $\left(\underline{p}, p_{3}\right)$ is lower than $T_{1}$. Because of this, they ignore $T_{1}$ and choose $\underline{R}(p)$ as their reservation wage. For all these men, the chosen reservation wage is higher than $T_{2}$, therefore Set 2 women marry them irrespective of whether they are employed or unemployed. This leads to the formation of Class 2 partnerships. Importantly, there is no marriage premium associated with these men.

(ii) if $p<p^{*}<p_{3}$, men with $p \in\left(p^{*}, p_{3}\right)$ cannot marry Set 1 women but are nonetheless accepted by Set 2 women, even while jobless. Consequently, the marriage wage premium for these men is again zero. Sadly, men with $p \in\left(p, p^{*}\right)$ can never get married.

\section{Empirical evidence}

Theorem 1 offers clear predictions about the ranking of marriage premia across men of different productivity - that less educated cohorts should be characterised by a higher marriage wage premium $(M P)$. In turn, the results in Section 4 strongly suggest a marriage market characterised by classes where this pattern of MP is broken by a bottom class characterised by a zero marriage wage premium $(M P)$. Together, these theoretical predictions offer a good basis for an empirical test.

Our primary aim in this section is to estimate the $M P$ for a heterogeneous male workforce in order to recognise patterns of $M P$ that could offer support to the theoretical framework, be it with or without two sided heterogeneity. We use educational attainment as proxy for productivity, with higher levels of education representing higher levels of productivity. We estimate our $M P$ by regressing wages on marital status, controlling for a range of other 
factors, using both OLS and fixed effects. The latter method uses the withintransformation to sweep out time-invariant individual heterogeneity and is recommended for estimating the $M P$ - for details, see Cornwell and Rupert (1995).

In addition, we also look for patterns of classes on the marriage market that exhibit the male wage premia suggested by our theoretical model.

\subsection{Data}

We use two sources of data from the UK: the National Child Development Survey (NCDS) and the British Household Panel Survey (BHPS). The NCDS is a cohort study that has followed a cohort of 17,000 individuals born in a single week in 1958 in England, Scotland and Wales. Data were collected on individuals throughout their lives and we use data from waves 4, 5, 6, 7 and 8 when the individuals were aged 23, 33, 42, 46 and 50. The BHPS was collected between 1991 and 2008 and covered England and Wales, as well as parts of Scotland (later all of Scotland) and Northern Ireland. Data were collected initially on around 5,000 households, leading to around 10,000 interviews. Individuals were followed over time, and as individuals moved into new households all individuals in the new households were also interviewed. We use data from all 18 waves of the BHPS.

There are several advantages to using these two datasets. Firstly, since they are longitudinal, it is possible to control for time invariant unobservable heterogeneity by using fixed effects estimations methods. Secondly, they contain information required for the estimation of wage equations, including information on individual educational attainment. Thirdly, they provide different insights into the empirical problem. The BHPS contains individuals from different ages, meaning that for different age cohorts there may be different labour market experiences. The NCDS contains individuals of the same age, so the cohort experience will be common across all individuals. Given the difference in the characterisitcs of the data, using both databases can constitute a test of the robustness of the empirical results.

For our estimation we have focussed on men who are either single or are in their first marriage and who are working full time. Individuals are categorised into four groups by education status. The four groups are 1) No 
qualifications, 2) School leavers qualifications (qualifications obtained at the school leaving age of 16), 3) Higher school leavers qualifications (these are qualifications that are above those for age 16 but lower than degree level, and 4) Higher education qualifications - degree and above.

The key outcome variable for this study is wages. In the NCDS individuals are asked to report their usual net pay and the period that this applies to allowing us to calculate net pay per week which we then deflate (to 1987 prices) and log. For the BHPS we construct logged, deflated (to 1987 prices) monthly income. We also include controls for age (BHPS), region of residence, social class (a marker of status based on occupation), health status ${ }^{12}$, sector of employment and wave dummies. For the BHPS we also have full information across waves on size of employer, experience and union status. Summary statistics for the two samples are given in Table 1.

[Table 1 about here]

In Table 1 we see that individuals in the NCDS sample are more likely to be married than those in the BHPS. This may be due to the age difference between the two datasets, with the average age in the BHPS sample being around 34, whereas the NCDS sample were all 50 in 2008. Other differences include the proportion of the population with a degree, reflecting greater educational opportunities for younger age groups in the BHPS data. Also, the proportion of individuals reporting excellent health is higher in the NCDS, reflecting the different categories available when answering the self-assessed health question. Lastly we can see that in the BHPS a greater proportion work in the private sector and there is a larger share of the population grouped around higher social classes.

Tables 2, 3, 4 and 5 give the summary statistics by each of the education groups. We can see that individuals with degrees have, on average higher incomes, are in better health, less likely to be in the private sector and more likely to be of high social class. As we move down the educational groups income falls and individuals are more likely to be in a lower social class classification.

[Tables 2, 3, 4 and 5 about here]

\footnotetext{
${ }^{12}$ For the BHPS in wave 9 the health question was different from the other waves, we estimate models including and excluding wave 9 data and find that it makes little difference to the results.
} 


\subsection{Methods}

Initially, we estimate the marriage wage premium for all individuals using fixed effects, which controls for unobservable heterogeneity and also removes all time invariant variables, such as education status, from the model. We follow Cornwell and Rupert (1995) and estimate a wage equation of the form:

$$
\ln \left(w_{i t}\right)=\beta M_{i t}+\gamma^{\prime} X_{i t}+\alpha_{i}+\varepsilon_{i t},
$$

where the dependent variable is the log of income, $M_{i t}$ is an indicator showing whether an individual is married, and $X_{i t}$ is a matrix of control variables. ${ }^{13}$ In turn, $\alpha_{i}$ captures time-invariant individual heterogeneity and $\varepsilon_{i t}$ is the standard idiosyncratic error term. The unknown parameter $\beta$ is to estimated and interpreted: if a marriage wage premium exists then $\beta$ will be positive and significant.

\subsection{Results}

We estimated the equation above for the full sample and for each of education categories, bearing in mind the results from Theorem 1 (that the MP increases for less productive cohorts throughout the whole range), and Theorem 2 (that the increase in MP for less productive cohorts is broken in the last class, which is characterised by a zero male marriage premium).

The results are presented in Table 6 . The first row of results shows the marriage wage premium for the whole samples for the NCDS and the BHPS. The remaining rows show the results for each of the education groups.

[Table 6 about here]

Overall, we can see the existence of a marriage wage premium and that is highly significant, for the whole sample. When we consider the estimation by education group, and starting with the most educated men, we observe the gradient, just as predicted by both versions of our model. In both samples, the estimate is close to zero and not significant among men with degree. It becomes significant and increasing as we move to men with "below degree" and this pattern continues as we move to "school leavers".

\footnotetext{
${ }^{13}$ For both datasets these are: region of residence, wave dummies, sector of employment, social class, health status and family size. The BHPS also includes age, size of employer, experience and union status.
} 
However, there is a break in this pattern as we move to men with no qualifications, for whom the estimates are again insignificant, reflecting no marriage premium among these men. This finding suggests the existence of classes, whereby women in the lowest class and men with lowest productivity/education have no option except to marry each other - and they do so regardless of their characteristics.

In Table 7 we investigate the characteristics of men's partners in order to check if they differ across the productivity range. In particular, we focus on the characteristics of the partners of men in the lowest productivity group. Our conjecture regarding classes and the existence of no marriage wage premium for the lowest productivity group would be supported if women married to these men display worse characteristics, on average, than women married to men in the other productivity groups. ${ }^{14}$

For the NCDS study we have data on the partner's years of education and the partner's social class. For the latter measure we simply use the 6 point scale (where 1 is the highest social class and 6 is the lowest social class) in our regression. Since our aim is simply to highlight differences between prodictivity groups, it does not matter that we linearise this variable. For the BHPS we have information on a partner's highest education qualification, a partner's hourly income and a partner's parental social class. For education we focus on those with no qualifications and those with a degree (the extremes of the education qualifications) and for social class we again linearise the 6 point scale, where 1 is the highest social class and 6 is the lowest social class.

[Table 7 about here]

Examining Table 7, we can see that in both data sets, the lowest productivity men (those with no qualifications) are married to women with the worst characteristics, whichever way they are measured. Men with no qualifications are married to women with lower average years of education (in the NCDS) or women who are less likely to have a degree and more likely to have no qualification (in the BHPS). These women have, on average, lower social class status (NCDS) or their parental social class status is significantly lower (BHPS). For the BHPS we can also see that if these women are working they earn, on average, a lower average wage than women married to men in

\footnotetext{
${ }^{14}$ The sample sizes do not match our earlier analysis since the data for partners is not complete, leading to a number of missing cases.
} 
higher productivity groups. These results provide empirical support for the existence of classes, where men in the lowest productivity group and women in the lowest class have no option but to marry each other. A consequence of that marriage pattern would be the absence of any male marriage wage premium in the bottom class, a conjecture that is in accordance with our empirical results.

\section{Conclusion}

In this paper we argue that search frictions in labour and marriage markets can explain the puzzling phenomenon of male marriage premium. If men looking for jobs also take into account the expectations of women in the marriage market, their optimal reservation wages could end up being less than the wage required to make them marriageable. This is simply because, if the male wage that ensures success in the marriage market is too high, men may end up setting a relatively low reservation wage. Of course, this in itself does not mean that they are all confined to remain single. Some of them may still land jobs with marriageable wages. This, together with the low reservation wage creates a wedge between wages earned by married and single men: the male marriage premium.

At the heart of our explanation lies the fact that behaviour and outcomes in the labour market may be determined by expectations in the marriage market (and vice-versa). As in frictional labour markets earned wages are essentially determined by reservation wages set by job seekers, and in turn these earned wages affect the marriage prospects of men, the marriage premium arises naturally in a search equilibrium.

Importantly, in our story men are able to get married because they earn high enough wages, and not the other way round. In other words, we rule out the scenario according to which married men earn higher wages (due to an ex-post productivity increase generated by specialisation with a household household specialisation).

Equally importantly, the model allows us to examine the role of ex-ante productivity differences. Using a framework that incorporates male productivity heterogeneity, we establish that the marital wage gap can be an equilibrium outcome. This suggests that productivity differentials are not necessary 
for explaining such marital premia. Indeed, the wage gap can occur within each productivity type. Nonetheless, differences between the wages of married and single men remains a possibility across types too, and in that case these premia can be ranked in an empirically relevant manner. Furthermore, this also shows that productivity heterogeneity is not a sufficient condition either for a positive marriage premium: male reservation wage may very well match the level required for successful marriage, in which case the marital wage gap is zero.

Allowing for two-sided heterogeneity (where women also differ but this time in terms of attractiveness in the marriage market), leads to further insights in terms of the endogenous formation of marriage classes, which in turn displays patterns of male marital premia that can again be tested using data. More specifically, by considering the reservation wage strategies of men, we endogenise the range of characteristics (i.e. wages) on the male side, which in turn leads to the emergence of marital classes. We construct and establish the existence of a search equilibrium with class formation, fully characterise it in terms of marriage wage patterns across classes, and show that the bottom class will always contain men with zero marriage premium.

All these predictions offer a rich basis for an empirical test of the theoretical model. We carry out such an empirical investigation and the results seem to support the search theoretical explanation of marriage premium. In particular, we find evidence that marriage premia follow the patterns across productivity types suggested by our model, while men with very low socioeconomic characteristics exhibit zero marriage premium and are in partnerships with similarly below average women (pointing to the existence of a bottom marital class).

It is also worth pointing out that our empirical analysis constitutes (as far as we know) the first attempt at finding evidence for the search theoretic explanation of marriage premium. Given the simplicity of our model and the strenght of its theoretical predictions, more empirical tests are needed. We believe that further work (both theoretical and applied) that investigates various outcomes in the context of inter-linked frictional markets represents a very promising research project. 


\section{References}

[1] Antonovics, K., and R. Town, 2004. "Are all the good men married? Uncovering the sources of the marital wage premium." American Economic Review 94: 317-321.

[2] Bardasi, E., and M. Taylor, 2008. "Marriage and wages: a test of the specialization hypothesis". Economica 75: 569-591.

[3] Becker, G., 1973. "A theory of marriage: Part I." Journal of Political Economy 81, 813-846.

[4] Becker, G., 1974. "A theory of marriage: Part II." Journal of Political Economy 82, S11-S26.

[5] Becker, G., 1985. "Human capital, effort and the sexual division of labour." Journal of Labor Economics 3, S33-S58.

[6] Becker, G.,1991. A Treatise on the Family. Cambridge MA, Harvard University Press.

[7] Blackburn, M., and S. Korenman, 1994. "The declining marital-status earnings differential." Journal of Population Economics 7: 249-270.

[8] Blundell, R., M. Costa Dias, C. Meghir and J.M. Shaw, 2015. "Female labour markets, labour supply, human capital and welfare reform", NBER Working Papers Series.

[9] Bonilla, R. and F. Kiraly, 2013. "Marriage wage premium in a search equilibrium", Labour Economics 24, 107-115.

[10] Bonilla, R., F. Kiraly, and J. Wildman, 2015. "Beauty Premium and Marriage Premium in Search Equilibrium: Theory and Empirical Test", mimeo, Newcastle University.

[11] Burdett, K. and M. Coles, 1997. "Marriage and class", Quarterly Journal of Economics 112, 141-168.

[12] Chiappori, PA., M. Iyigun, and Y. Weiss, 2007. "Investment in schooling and the marriage market." American Economic Review 99: 1689-1713. 
[13] Chun, H. and I. Lee, 2001. "Why do married men earn more: productivity or marriage selection?" Economic Inquiry 39, 307-319.

[14] Cornwell, C., and P. Rupert, 1995. "Marriage and earnings", Economic Review, Federal Reserve Bank of Cleveland, issue Q IV, 10-20.

[15] Daniel, K., 1995. "The marriage premium." In: Becker, G., Tomassi, M. and Ierulli, K. (Eds.), The New Economics of Human Behavior, Cambridge: Cambridge University Press.

[16] Davies, H., and R. Peronaci, 1997. "Male wages and living arrangements: recent evidence for Britain." Birkbeck College DP in Economics 5/97, University of London.

[17] Ginther, D.K., and M. Zavodny, M., 2001. "Is the male marriage premium due to selection? The effect of shotgun weddings on the return to marriage." Journal of Population Economics 14 (2), 313-328.

[18] Gould, E.D., and M.D. Paserman, 2003. "Waiting for Mr. Right: rising wage inequality and declining marriage rates." Journal of Urban Economics 53 (2), 257-281.

[19] Gray, J.S., 1997. "The fall in men's return to marriage: declining productivity effects or changing selection?" Journal of Human Resources $32(3), 481-504$.

[20] Grossbard-Shechtman, S.A., and S. Neuman, 2003. "Marriage and work for pay." In: Grossbard-Shechtman, S.A. (Ed.). Marriage and the Economy. Cambridge, UK: Cambridge University Press.

[21] Hersch, J., 2003. "Marriage, hosehold production, and earnings." In: Grossbard-Shechtman, S.A. (Ed.). Marriage and the Economy. Cambridge, UK: Cambridge University Press.

[22] Hersch, J., and L.S. Stratton, 2000. "Household specialization and the male marriage wage premium." Industrial and Labor Relations Review 54 (1), 78-94.

[23] Korenman, S., and D. Neumark, 1991. "Does marriage really make men more productive?" Journal of Human Resources 26, 282- 307. 
[24] Loh E. S., 1996. "Productivity differences and the marriage wage premium for white males." Journal of Human Resources 31 (3), 566-589.

[25] Loughran, D., 2002. "The effect of male wage inequality on female age at first marriage." The Review of Economics and Statistics 84 (2), 237-250.

[26] Loughran, D., and J. Zissimopoulos, 2009. "Why wait? The effect of marriage and childbearing on the wages of men and women." Journal of Human Resources 44 (2), 326-349.

[27] Mincer, J., and S. Polachek, 1974. "Family investments in human capital: earnings of women." Journal of Political Economy 82: S76-S108.

[28] Nakosteen, R.A. and M.A. Zimmer, 1987. "Marital status and the earnings of young men: a model with endogenous selection." Journal of Human Resources 22, 248-268.

[29] Nakosteen, R.A. and M.A. Zimmer, 1997. "Men, money and marriage: Are high earners more prone than low earners to marry?" Social Science Quarterly 78.

[30] Oppenheimer, V.K., 1988. "A theory of marriage timing." The American Journal of Sociology 94, 563-591.

[31] Oppenheimer, V.K., and V. Lew, 1995. "American marriage formation in the 1980s: how important was women's economic independence?" In: Mason, K.O., Jensen, A.-M. (Eds.), Gender and Family Change in Industrialized Countries. Clarendon Press, Oxford, England.

[32] Ponthieux, S. and D. Meurs, 2014. "Gender Inequality". In: Atkinson, A.B. and F. Bourguignon (Eds.), Handbook of Income Distribution (Vol. 2A). North Holland, Amsterdam.

[33] Schoeni, R., 1995. "Marital status and earnings in developed countries." Journal of Population Economics 8, 351-359. 
Table 1: Summary statistics

\begin{tabular}{lcccc}
\hline \hline \multicolumn{1}{c}{ Variable } & $\begin{array}{c}\text { Mean } \\
\text { NCDS }\end{array}$ & Std. Dev. & $\begin{array}{c}\text { Mean } \\
\text { BHPS }\end{array}$ & Std. Dev \\
\hline log real weekly income & 5.166 & 0.514 & & \\
log real monthly income & & & 6.827 & 0.489 \\
married & 0.739 & 0.439 & 0.591 & 0.492 \\
education - degree & 0.127 & 0.333 & 0.216 & 0.412 \\
education - below degree & 0.353 & 0.478 & 0.341 & 0.474 \\
education - school leaver (16) & 0.431 & 0.495 & 0.321 & 0.467 \\
education - no qualifications & 0.089 & 0.284 & 0.122 & 0.327 \\
age & & & 34.511 & 8.558 \\
excellent health & 0.826 & 0.379 & 0.329 & 0.47 \\
private sector & 0.702 & 0.458 & 0.821 & 0.383 \\
social class 1 (high) & 0.071 & 0.257 & 0.081 & 0.273 \\
social class 2 & 0.305 & 0.46 & 0.325 & 0.469 \\
social class 3 non-manual & 0.166 & 0.372 & 0.153 & 0.36 \\
social class 3 manual & 0.31 & 0.463 & 0.282 & 0.45 \\
social class 4 & 0.113 & 0.316 & 0.13 & 0.336 \\
social class 5 (low) & 0.035 & 0.184 & 0.029 & 0.168 \\
experience (days) & & & 1714.625 & 2055.932 \\
union & & & 0.415 & 0.493 \\
\hline $\mathrm{N}$ & 7380 & & 19644 & \\
\hline \hline
\end{tabular}


Table 2: Summary statistics - Education, degree

\begin{tabular}{lcccc}
\hline \hline \multicolumn{1}{c}{ Variable } & $\begin{array}{c}\text { Mean } \\
\text { NCDS }\end{array}$ & Std. Dev. & $\begin{array}{c}\text { Mean } \\
\text { BHPS }\end{array}$ & Std. Dev \\
\hline log real weekly income & 5.487 & 0.544 & & \\
log real monthly income & & & 7.106 & 0.524 \\
married & 0.748 & 0.434 & 0.545 & 0.498 \\
age & & & 34.485 & 8.176 \\
excellent health & 0.875 & 0.331 & 0.386 & 0.487 \\
private & 0.553 & 0.497 & 0.713 & 0.453 \\
social class 1 (high) & 0.232 & 0.422 & 0.24 & 0.427 \\
social class 2 & 0.568 & 0.496 & 0.551 & 0.497 \\
social class 3 non-manual & 0.096 & 0.295 & 0.129 & 0.335 \\
social class 3 manual & 0.035 & 0.184 & 0.048 & 0.214 \\
social class 4 & 0.045 & 0.207 & 0.031 & 0.172 \\
social class 5 (low) & 0.025 & 0.155 & 0.002 & 0.043 \\
experience (days) & & & 1188.782 & 1498.924 \\
union & & & 0.377 & 0.485 \\
\hline $\mathrm{N}$ & 937 & & 4251 & \\
\hline
\end{tabular}

Table 3: Summary statistics - Education, below degree

\begin{tabular}{lcccc}
\hline \hline \multicolumn{1}{c}{ Variable } & $\begin{array}{c}\text { Mean } \\
\text { NCDS }\end{array}$ & Std. Dev. & $\begin{array}{c}\text { Mean } \\
\text { BHPS }\end{array}$ & Std. Dev \\
& 5.267 & 0.506 & & \\
\hline log real weekly income & & & 6.844 & 0.46 \\
log real monthly income & & & 0.592 & 0.492 \\
married & 0.742 & 0.438 & 34.184 & 8.54 \\
age & & & 0.345 & 0.476 \\
excellent health & 0.848 & 0.359 & 0.809 & 0.393 \\
private & 0.690 & 0.462 & 0.063 & 0.242 \\
social class 1 (high) & 0.086 & 0.281 & 0.368 & 0.482 \\
social class 2 & 0.38 & 0.485 & 0.19 & 0.392 \\
social class 3 non-manual & 0.172 & 0.377 & 0.281 & 0.45 \\
social class 3 manual & 0.274 & 0.446 & 0.084 & 0.277 \\
social class 4 & 0.07 & 0.255 & 0.014 & 0.118 \\
social class 5 (low) & 0.018 & 0.134 & 1657.673 & 1960.923 \\
experience (days) & & & 0.438 & 0.496 \\
union & & & 6701 & \\
\hline $\mathrm{N}$ & 2606 & & & \\
\hline
\end{tabular}


Table 4: Summary statistics - Education, school leaver (16)

\begin{tabular}{lcccc}
\hline \hline \multicolumn{1}{c}{ Variable } & $\begin{array}{c}\text { Mean } \\
\text { NCDS }\end{array}$ & Std. Dev. & $\begin{array}{c}\text { Mean } \\
\text { BHPS }\end{array}$ & Std. Dev \\
& 5.056 & 0.444 & & \\
\hline log real weekly income & & & 6.709 & 0.42 \\
log real monthly income & & & 0.575 & 0.494 \\
married & 0.741 & 0.438 & 33.34 & 8.497 \\
age & & & 0.297 & 0.457 \\
excellent health & 0.808 & 0.394 & 0.875 & 0.33 \\
private & 0.735 & 0.441 & 0.02 & 0.142 \\
social class 1 (high) & 0.022 & 0.148 & 0.212 & 0.409 \\
social class 2 & 0.208 & 0.406 & 0.163 & 0.37 \\
social class 3 non-manual & 0.199 & 0.399 & 0.378 & 0.485 \\
social class 3 manual & 0.399 & 0.49 & 0.193 & 0.395 \\
social class 4 & 0.134 & 0.341 & 0.033 & 0.178 \\
social class 5 (low) & 0.037 & 0.189 & 1849.076 & 2123.723 \\
experience (days) & & & 0.416 & 0.493 \\
union & & & 6297 & \\
\hline $\mathrm{N}$ & 3183 & & & \\
\hline
\end{tabular}

Table 5: Summary statistics - Education, no qualifications

\begin{tabular}{lcccc}
\hline \hline \multicolumn{1}{c}{ Variable } & $\begin{array}{c}\text { Mean } \\
\text { NCDS }\end{array}$ & Std. Dev. & $\begin{array}{c}\text { Mean } \\
\text { BHPS }\end{array}$ & Std. Dev \\
\hline log real weekly income & 4.834 & 0.466 & & \\
log real monthly income & & & 6.591 & 0.435 \\
married & 0.702 & 0.458 & 0.714 & 0.452 \\
age & & & 38.55 & 8.252 \\
excellent & 0.755 & 0.43 & 0.265 & 0.441 \\
private & 0.797 & 0.403 & 0.906 & 0.292 \\
social class 1 (high) & 0.017 & 0.129 & 0.009 & 0.093 \\
social class 2 & 0.099 & 0.299 & 0.103 & 0.304 \\
social class 3 non-manual & 0.086 & 0.28 & 0.066 & 0.248 \\
social class 3 manual & 0.414 & 0.493 & 0.446 & 0.497 \\
social class 4 & 0.277 & 0.448 & 0.268 & 0.443 \\
social class 5 (low) & 0.107 & 0.309 & 0.109 & 0.311 \\
experience (days) & & & 2453.813 & 2641.215 \\
union & & & 0.419 & 0.493 \\
\hline $\mathrm{N}$ & 654 & & 2395 & \\
\hline \hline
\end{tabular}


Table 6: Marriage wage premium results

\begin{tabular}{|c|c|c|c|c|}
\hline & \multirow{2}{*}{$\begin{array}{c}\text { NCDS } \\
\beta\end{array}$} & \multicolumn{3}{|c|}{$\overline{\overline{B H P S}}$} \\
\hline & & $\mathbf{N}$ & $\beta$ & $\mathbf{N}$ \\
\hline \multicolumn{5}{|l|}{ Full sample } \\
\hline Marriage wage premium & $\begin{array}{c}0.091^{* * *} \\
(0.018)\end{array}$ & 7380 & $\begin{array}{c}0.074^{* *} \\
(0.046)\end{array}$ & 19644 \\
\hline \multicolumn{5}{|l|}{ Education - degree } \\
\hline Marriage wage premium & $\begin{array}{c}0.022 \\
(0.046)\end{array}$ & 937 & $\begin{array}{l}-0.034 \\
(0.074)\end{array}$ & 4251 \\
\hline \multicolumn{5}{|l|}{ Education - below degree } \\
\hline Marriage wage premium & $\begin{array}{c}0.062^{* *} \\
(0.029)\end{array}$ & 2606 & $\begin{array}{c}0.08^{*} \\
(0.047)\end{array}$ & 6701 \\
\hline \multicolumn{5}{|l|}{ Education - school leaver } \\
\hline Marriage wage premium & $\begin{array}{c}0.081^{* * *} \\
(0.024)\end{array}$ & 3183 & $\begin{array}{c}0.165^{*} \\
(0.091)\end{array}$ & 6297 \\
\hline \multicolumn{5}{|l|}{ Education - no qualifications } \\
\hline Marriage wage premium & $\begin{array}{l}-0.011 \\
(0.069)\end{array}$ & 654 & $\begin{array}{c}0.042 \\
(0.064)\end{array}$ & 2395 \\
\hline
\end{tabular}

All models include controls for region of residence, wave dummies, sector of employment, social class, health status and family size. BHPS models also include controls for age, size of employer, experience and union status. 
Table 7: Partner's Characteristics

\begin{tabular}{|c|c|c|c|c|c|c|}
\hline & \multicolumn{2}{|c|}{ NCDS } & \multicolumn{4}{|c|}{ BHPS } \\
\hline & $\begin{array}{c}\text { Partner's years } \\
\text { of Education }\end{array}$ & $\begin{array}{c}\text { Partner's } \\
\text { Social Class }\end{array}$ & $\begin{array}{c}\text { Partner has } \\
\text { no qualifications }\end{array}$ & $\begin{array}{c}\text { Partner has } \\
\text { a degree }\end{array}$ & $\begin{array}{l}\text { Partner's hourly } \\
\text { income }\end{array}$ & $\begin{array}{c}\text { Partner's parental } \\
\text { social class }\end{array}$ \\
\hline $\begin{array}{r}\text { Education - } \\
\text { degree }\end{array}$ & $\begin{array}{c}20.10 * * * \\
(0.105)\end{array}$ & $\begin{array}{c}2.403^{* * *} \\
(0.034)\end{array}$ & $\begin{array}{c}0.027 * * * \\
(0.003)\end{array}$ & $\begin{array}{c}0.508 * * * \\
(0.011)\end{array}$ & $\begin{array}{c}6.382^{* * *} \\
(0.024)\end{array}$ & $\begin{array}{c}2.765^{* * *} \\
(0.029)\end{array}$ \\
\hline $\begin{array}{l}\text { Education } \\
\text { below degree }\end{array}$ & $\begin{array}{c}18.31^{* * *} \\
(0.086)\end{array}$ & $\begin{array}{c}2.886^{* * *} \\
(0.021)\end{array}$ & $\begin{array}{c}0.111^{* * *} \\
(0.005)\end{array}$ & $\begin{array}{c}0.145^{* * *} \\
(0.006)\end{array}$ & $\begin{array}{c}6.031^{* * *} \\
(0.018)\end{array}$ & $\begin{array}{c}3.542^{* * *} \\
(0.022)\end{array}$ \\
\hline $\begin{array}{l}\text { Education - } \\
\text { school leaver }\end{array}$ & $\begin{array}{c}16.89^{* * *} \\
(0.047)\end{array}$ & $\begin{array}{c}3.070^{* * *} \\
(0.019)\end{array}$ & $\begin{array}{c}0.168 * * * \\
(0.006)\end{array}$ & $\begin{array}{c}0.079 * * * \\
(0.005)\end{array}$ & $\begin{array}{c}5.909 * * * \\
(0.019)\end{array}$ & $\begin{array}{c}3.757^{* * *} \\
(0.021)\end{array}$ \\
\hline $\begin{array}{l}\text { Education } \\
\text { - no qualifications }\end{array}$ & $\begin{array}{c}16.35^{* * *} \\
(0.113)\end{array}$ & $\begin{array}{c}3.349^{* * *} \\
(0.048)\end{array}$ & $\begin{array}{c}0.377^{* * * *} \\
(0.012)\end{array}$ & $\begin{array}{c}0.037^{* * *} \\
(0.005)\end{array}$ & $\begin{array}{c}5.824^{* * *} \\
(0.025)\end{array}$ & $\begin{array}{c}4.078 * * * \\
(0.031)\end{array}$ \\
\hline $\mathrm{N}$ & 5365 & 4646 & 10776 & 10776 & 8724 & 9602 \\
\hline
\end{tabular}


Appendix A: $\quad R_{i}(<T)$ and $\widehat{T}_{i}$

For $T \in\left(\widehat{T}_{i}, \bar{w}_{i}\right]$, and given $V_{i}^{S}\left(R_{i}\right)=J_{i}$, the reservation wage solves:

$$
\begin{gathered}
\frac{R_{i}}{r+\delta}=\frac{\lambda_{0}}{r+\delta+\lambda_{0}} F\left(R_{i}\right) \int_{\underline{w}_{i}}^{R_{i}} \frac{R_{i}}{r+\delta} d F_{i}\left(w \mid w<R_{i}\right)+ \\
+\frac{\lambda_{0}}{r+\delta+\lambda_{0}}\left[F_{i}(T)-F_{i}\left(R_{i}\right)\right] \int_{R_{i}}^{T} \frac{w}{r+\delta} d F_{i}\left(w \mid R_{i}<w<T\right)+ \\
+\frac{\lambda_{0}}{r+\delta+\lambda_{0}}\left[1-F_{i}(T)\right] \int_{T}^{\bar{w}_{i}}\left[\frac{w}{r+\delta}+\frac{\lambda n}{(r+\delta)(r+\delta+\lambda n)} y\right] d F_{i}(w \mid w>T) .
\end{gathered}
$$

After some manipulations, this simplifies to:

$$
R_{i}=\frac{\lambda_{0}}{r+\delta} \int_{R_{i}}^{\bar{w}_{i}}\left[w-R_{i}\right] d F_{i}(w)+\frac{\lambda_{0}\left[1-F_{i}(T)\right] \lambda n}{(r+\delta)(r+\delta+\lambda n)} y .
$$

Further integration by parts leads to:

$$
R_{i}=\frac{\lambda_{0}}{r+\delta}\left[\int_{R_{i}}^{\bar{w}_{i}}\left[1-F_{i}(w)\right] d w+\frac{\left[1-F_{i}(T)\right] \lambda n}{r+\delta+\lambda n} y\right] \quad(<T) .
$$

The expression for $\widehat{T}_{i}$ follows immediately:

$$
\widehat{T}_{i}=\frac{\lambda_{0}}{r+\delta}\left[\int_{\widehat{T}_{i}}^{\bar{w}_{i}}\left[1-F_{i}(w)\right]+\frac{\left[1-F\left(\widehat{T}_{i}\right)\right] \lambda n}{r+\delta+\lambda n} y\right] \quad\left(>\underline{R}_{i}\right) .
$$

With no search frictions in the labour market $\left(\lambda_{0} \rightarrow \infty\right)$, clearly $R_{i}(T)=$ $\bar{w}_{i}$. Note that $\widehat{T}_{i}$ is a function of $y$. Since $\partial F_{i}\left(\widehat{T}_{i}\right) / \partial \widehat{T}_{i}>0$, it is true that $\partial \widehat{T}_{i} / \partial y>0$. One can solve for $y$ to get:

$$
y=\frac{(r+\delta+\lambda n)\left[(r+\delta) \widehat{T}_{i}-\lambda_{0} \int_{\widehat{T}_{i}}^{\bar{w}_{i}}\left[1-F_{i}(w)\right] d w\right]}{\lambda_{0} \lambda n\left[1-F_{i}\left(\widehat{T}_{i}\right)\right]} .
$$


Then, $\lim _{\widehat{T}_{i} \rightarrow \bar{w}} y=\infty$ and, since $\widehat{T}_{i}$ is an invertible function, $\lim _{y \rightarrow \infty} \widehat{T}_{i}=\bar{w}_{i}$.

\section{Appendix B: Other equilibria}

Assume $\widehat{T}_{H}>\bar{w}_{L}$. With $\frac{\partial T}{\partial x}>0$ and $\underline{R}_{H}<\widehat{T}_{L}<\bar{w}_{L}<\widehat{T}_{H}$, it follows that $\underline{x}<\widehat{x}_{L}<\bar{x}<\widehat{x}_{H}$.

Now assume $\widehat{T}_{H}<\bar{w}_{L}$. For $x \in\left[\underline{x}, \widehat{x}_{H}\right]$, there is always a unique equilibrium where only employed men can get married and both types do. The range of possible equilibra and the necessary and sufficient conditions in terms of $x$ are as follows:
(a) An equilibrium with $M P_{L}>M P_{H}>0$ obtains iff $x>\widehat{x}_{H}$.
(b) An equilibrium with $M P_{L}>0$ and $M P_{H}>0$ obtains iff $\bar{x}<x<$
$\widehat{x}_{H}$
$x<\bar{x}$
(c) An equilibrium with $M P_{L}>0$ and $M P_{H}=0$ obtains iff $\widehat{x}_{L}<$
(d) An equilibrium with $M P_{i}=0(i=H, L)$ obtains iff $\underline{x}<x<\widehat{x}_{L}$.

\section{Appendix C: $\quad$ Proof of Theorem 2 (numerical solution)}

As all choice variables are continuous, it is enough to show that a two-class equilibrium with the desirable properties exists for a given set of parameters. Consider the following values for the relevant parameters of the model: $\lambda_{0}=$ $1.5 ; \delta=0.1 ; r=0.1 ; \lambda=1 ; \bar{p}=200 ; z=200 ; u=0.1 ; y=0.4 ; \bar{y}=1$. Given a range of productivities $[p, \bar{p}]$ where each productivity has the same measure $u$ of unemployed, for men also we are dealing with an uniform distribution of types. Finally, let the distribution of wages be uniform as well, with support on $[p, p+z]$ for each type $p$.

With two classes (by construction), we have: $n_{1}=\left[1-H\left(y_{1}\right)\right]$ and $n_{2}=$ $H\left(y_{1}\right)$.Also, note that women's arrival rate is very sensitive to changes in $u$ and the productivity range.

\section{Equilibrium:}

We pick the equilibrium that is most difficult to construct, i.e. the one with $p_{2}>\bar{p}$. Since $p_{2}$ is endogenous, showing that such an equilibrium exists is not trivial precisely because of this constraint on $\bar{p}$. 
First, note that with the above inequality constraint, some of the indicator functions in our value functions will be zero. Second, we need $y_{2}<y$. With our numerical values, this inequality is indeed satisfied. Next, we compute $y_{1}$ :

$$
y_{1}=0.615619
$$

Now we can compute $T_{1}$, given that $p_{3} \equiv T_{1}-z$. We obtain:

$$
T_{1}=327.08844
$$

This is clearly lower than the highest wage in the market, which is $\bar{p}+z=$ 400.

Next, we compute $p_{2}$ and then show that it is indeed higher than $\bar{p}$. Making use of the equation for $R(p)$ and equating it to $T$, we get $\widehat{T}(p)$. Following that, solve $\widehat{T}(p)=T_{1}$ to obtain:

$$
p_{2}=258.944839(>\bar{p})
$$

Recall that $p_{3}$ was defined by $T_{1}-z$, so $p_{3}=127.08844$. This allows us to compute the value of being single for a Set 2 woman $\left(W_{2}^{S}\right)$, as a function of (any) $\underline{p}$. We can then compare this with $\frac{R(p)}{r+\delta}$ (the value of being married to a $\underline{p}$ man). Clearly, we need the latter to be greater than the former. The explicit solution to $W_{2}^{S}$ is:

$$
W_{2}^{S}=\frac{\int_{p_{3}}^{\bar{p}}\left[N_{p}^{\prime \prime} \int_{R(p)}^{T_{1}} \frac{w}{r+\delta} d G_{p}^{\prime}(w)\right] d p+u \int_{\underline{p}}^{\bar{p}} \frac{\underline{R}(p)}{r+\delta} d p}{r+\delta+u(\bar{p}-\underline{p})+\int_{p_{3}}^{\bar{p}} N_{p}^{\prime \prime}\left[G_{p}^{\prime}\left(T_{1}\right)-G_{p}^{\prime}(R(p))\right] d p},
$$

where $G_{p}^{\prime}\left(T_{1}\right)-G_{p}^{\prime}(R(p))=1-0=1$.

We find that $W_{2}^{S}<\frac{\underline{R}(\underline{p})}{r+\delta}$ holds for $\underline{p}>-61.786371\left(=p^{*}\right)$. This means that there is no lower (third) class if $p>-61.786371$. All men with $p$ between $\underline{p}$ and $p_{3}$ constitute a subset of Set $\overline{2}$ - the subset of men with zero marriage premium. These men are born in Set 2.

Overall, a non-empty set $\left(p^{*}, p_{3}\right)$, together with the condition on $y$ ensure the existence of our two-class equilibrium for a broad range of parameters. 